\title{
El marxismo y el movimiento de liberación homosexual: De la Socialdemocracia alemana a la Revolución Rusa
}

\author{
Marxism and the Homosexual Liberation Movement: \\ From German Social Democracy to the Russian Revolution
}

Daniel Gaido* - Cintia Frencia*

\begin{abstract}
Resumen: El presente trabajo analiza la despenalización de la homosexualidad como una medida adoptada por las revoluciones burguesas que, abandonado por los partidos burgueses a medida que el ascenso del proletariado impulsaba a la burguesía a buscar un compromiso con los terratenientes, el clero y las monarquías de los diferentes países, fue recogida como una demanda por los partidos obreros marxistas, tales como el Partido Socialdemócrata de Alemania antes de la Primera Guerra Mundial y el Partido Bolchevique en Rusia después de la revolución de octubre de 1917. El trabajo describe la cooperación entre la Socialdemocracia alemana y el Comité Científico-Humanitario dirigido por Magnus Hirschfeld a fin de despenalizar la homosexualidad mediante la eliminación del párrafo 175 del Código Penal alemán. El artículo describe también la despenalización de la homosexualidad en Rusia bajo Lenin, con la adopción del primer Código Penal soviético en junio de 1922, y la reversión de dicha medida en marzo de 1934, en el marco de la reacción estalinista. El delito de sodomía fue reintroducido en la legislación de la RSFSR en conjunción con medidas que en 1936 prohibieron el aborto e hicieron el divorcio menos accesible -es decir, con una opresión creciente no sólo de los varones homosexuales, sino también de las mujeres.
\end{abstract}

Palabras Clave: Despenalización de la Homosexualidad, Revolución Francesa; Partido Socialdemócrata de Alemania; Revolución Rusa; Partido Bolchevique; Estalinismo

Abstract: The present work analyzes the decriminalization of homosexuality as a measure
adopted by the bourgeois revolutions that, abandoned by the bourgeois parties as the rise
of the proletariat impelled the bourgeoisie to seek a compromise with the landlords, the
clergy and the monarchies of the different countries, was taken over as a demand by the
Marxist workers' parties, such as the Social Democratic Party of Germany before the First
World War and the Bolshevik Party in Russia after the Revolution of October 1917. The
article outlines the cooperation between Social Democracy and the Scientific-Humanitarian
Committee led by Magnus Hirschfeld in order to decriminalize homosexuality by removing

${ }^{*}$ Argentino, investigador adjunto del Consejo Nacional de Investigaciones Científicas y Técnicas (CONICET) y docente en la Universidad Nacional de Córdoba. Daniel Gaido es co-editor, junto con Richard B. Day, de Witnesses to Permanent Revolution: The Documentary Record (Brill, 2009) y Responses to Marx's Capital: From Rudolf Hilferding to Isaak. Illich Rubin (Brill, 2017). danielgaid@gmail.com

${ }^{*}$ Argentina, Docente en la Universidad Nacional de Córdoba. Cintia Frencia es coautora, junto con Daniel Gaido, de El marxismo y la liberación de las mujeres trabajadoras: de la Internacional de Mujeres Socialistas a la Revolución Rusa, Santiago de Chile: Editorial Ariadna, 2016, y del artículo "'A Clean Break': Clara Zetkin, the International Socialist Women's Movement and Feminism", International Critical Thought, Official publication of the Chinese Academy of Social Sciences (CASS), Vol. 8, No. 2, June 2018, pp. 1-27. cfrencia@gmail.com 
paragraph 175 of the German Penal Code. The article also describes the decriminalization of homosexuality in Russia under Lenin, with the adoption of the first Soviet Penal Code in June 1922, and the reversal of that measure in March 1934, within the framework of Stalinist reaction. The crime of sodomy was reintroduced into the legislation of the RSFSR in conjunction with measures that in 1936 prohibited abortion and made divorce less accessible - that is, with an increasing oppression not only of homosexual men, but also of women.

Keywords: Decriminalization of Homosexuality; French Revolution; Social Democratic Party of Germany; Russian Revolution; Bolshevik Party; Stalinism

Recibido: 12 agosto 2018 Aceptado: 4 diciembre 2019

\section{La despenalización de la homosexualidad en las revoluciones burguesas}

La despenalización de la homosexualidad nació con las revoluciones burguesas. En la Francia del antiguo régimen, la homosexualidad masculina, definida legalmente como "sodomía", era penalizada con la hoguera, y aunque esta pena era raramente aplicada, en fecha tan tardía como el 6 de julio de 1750 dos homosexuales, llamados Bruno Lenoir y Jean Diot, fueron ahorcados y quemados en la Place de Grève de Paris por haber sido encontrados teniendo sexo consensual una noche de enero en las sombras de la rue Montorgueil. Como ambos eran obreros, sin conexiones con el gobierno o con las clases dominantes, las autoridades aprovecharon para ejecutarlos públicamente como una advertencia a otros homosexuales. ${ }^{1}$ Criticando este resto de barbarie medieval, algunos de los philosophes y líderes de la Revolución Francesa, tales como Montesquieu, Condorcet y Anacharsis Cloots, negaron que el estado tuviera derecho a castigar la sodomía, siempre que las relaciones sexuales homosexuales tuvieran lugar entre adultos con consentimiento mutuo y en privado.

Las ideas revolucionarias sobre la despenalización de la homosexualidad finalmente se plasmaron en el Código Penal adoptado por la Asamblea Constituyente francesa en 1791, el cual derogó las leyes francesas contra la sodomía, como lo hizo más tarde el Código Penal soviético de 1922, por el simple expediente de no mencionar a la sodomía como un crimen punible El Código Penal de 1791 no incluía ningún delito sexual aparte de la violación, que la jurisprudencia francesa definía como una agresión cuya víctima era necesariamente mujer. ${ }^{2}$ Otro tanto sucedió con el Código Penal de 1810, adoptado bajo Napoleón.

La legislación del período revolucionario y napoleónico castigaba solamente la agresión sexual, los "delitos públicos contra la decencia", el estímulo al "libertinaje" y la "corrupción de jóvenes" de ambos sexos. En consecuencia, cuando los tribunales correccionales condenaban a los homosexuales, lo hacían por delitos públicos contra la decencia, es decir, por los mismos motivos que condenaban a los hombres y a las mujeres que tenían relaciones sexuales en público. La pena por este delito era generalmente varias semanas de prisión y/o expulsión del lugar de residencia.

\footnotetext{
1 "Bref, l'exécution a été faite pour faire un exemple, d'autant que l'on dit que ce crime devient très commun et qu'il y a beaucoup de gens à Bicêtre pour ce fait. Et comme ces deux ouvriers n'avaient point de relations avec des personnes de distinction, soit de la cour, soit de la ville, et qu'ils n'ont apparemment déclaré personne, cet exemple s'est fait sans aucune conséquence pour les suites." Edmond Jean François Barbier, Journal historique et anecdotique du règne de Louis $X V$, publié pour la Société de l'histoire de France d'après le manuscrit inédit de la bibliothèque nationale par A. de la Villegille, Paris : Jules Renouard et cie., 1847, tome troisième, p. 149.

2 Assemblée Nationale Constituante de France, Décret concernant le Code Pénal du 25 septembre 1791.
} 
Los tribunales de justicia napoleónicos rara vez juzgaban a homosexuales: hubo sólo cuatro casos conocidos, tres de los cuales involucraron a hombres que acosaban sexualmente a menores. El número de casos documentados es extraordinariamente bajo para un país de 30 millones de habitantes durante un período de veinticinco años, lo cual significa que la abrumadora mayoría de los homosexuales franceses deben haber conducido su vida sexual en forma completamente libre de acoso policial y procesos legales. La era revolucionaria y napoleónica fue una época de relativa libertad para los homosexuales franceses (Sibalis 1996).

\section{La criminalización de la homosexualidad en Prusia y en el Segundo Imperio Alemán}

En lo estados alemanes durante la Edad Media, el delito de sodomía (Sodomiterey) era castigado con la pena de muerte. Después de que el Código Penal de 1791 despenalizara la homosexualidad en Francia, Prusia redujo la pena por homosexualidad de muerte a prisión y destierro, con la introducción del Código de 1794 (Allgemeines Landrecht für die Preußischen Staaten). En el marco de sus conquistas, Napoleón exportó el Código Penal a los territorios anexados al oeste del Rin, donde su vigencia se mantuvo hasta la introducción del Código Penal alemán el 1 de enero 1872, así como a los Países Bajos. También Baviera siguió el modelo francés y despenalizó la homosexualidad en su Código de 1813. En Prusia, a partir del 1 de julio de 1851, la parte penal del Código de 1794 fue reemplazada por el Código Penal para los Estados Prusianos (Strafgesetzbuch für die Preußischen Staaten), el cual estipulaba como pena para la "fornicación antinatural" (widernatürliche Unzucht) la privación temporal de los derechos civiles -en lugar del destierro- en su párrafo 143 (Thiele 1909a, p. 1487).

Luego del triunfo de Prusia en la Guerra Austro-Prusiana de 1866, el partido tradicional de la burguesía liberal, el Partido Progresista Alemán (Deutsche Fortschrittsparter) se escindió en un ala derecha, el Partido Nacional Liberal, que abandonó el programa histórico del liberalismo en aras de un compromiso con los Junker (aristócratas) y la monarquía prusiana. El ala izquierda conformó en 1884 el Partido Liberal Alemán (Deutsche Freisinnigen Partei), el cual se dividió nuevamente en 1893 cuando una fracción buscó nuevamente un compromiso con la monarquía. El resultado de este abandono progresivo del programa revolucionario por los partidos de la burguesía fue que las demandas democráticas -la república, el sufragio universal, la milicia, la igualdad jurídica y política de la mujer, la separación de la iglesia y el estado, la despenalización de la homosexualidad, etc.- fueron recogidas por la organización de los trabajadores marxistas, el Partido Socialdemócrata.

A partir de 1868 comenzaron las deliberaciones sobre un Código Penal para la Confederación Alemana del Norte, creada como resultado del triunfo de Prusia en la Guerra Austro-Prusiana de 1866. En dicha ocasión, el gobierno reunió a una Deputation für das Medizinalwesen (Diputación para las Ciencias Médicas) a la que pertenecían médicos famosos como Virchow y Langenbeck, para que se pronunciara acerca del párrafo 143. Dicha comisión, en su informe del 24 de marzo de 1869, se declaró "incapaz de encontrar razones por las que, mientras que otros tipos de fornicación no aparecen en la legislación, se castigue el sexo con animales o entre hombres". Sin embargo, el dictamen de la comisión fue rechazado porque la "opinión pública" supuestamente no lo aceptaría, y el párrafo 143 del Código Penal Prusiano reapareció en el borrador del Código Penal para la Confederación Alemana del Norte como párrafo 152 (Thiele 1909a, p. 1487).

El 1 de enero de 1872, luego del triunfo alemán en la Guerra Franco-Prusiana, el Segundo Imperio Alemán fue creado bajo el liderazgo de Bismarck. El nuevo estado adoptó un Código Penal basado en el Código Penal de la Confederación Alemana del Norte, que había entrado en vigor un año antes. El párrafo 175 del nuevo Código Penal Imperial (Reichsstrafgesetz̧buch), que fue aprobado sin debate en el Reichstag en 1873, decía lo siguiente: "La fornicación antinatural (widernatürliche Unzucht) cometida entre personas de sexo masculino, o entre hombres y animales, se castigará con pena de cárcel; también 
se podrán retirar los derechos civiles." Así, el sexo consensual entre hombres se convirtió de nuevo en delito en Baviera y Hannover. El castigo mínimo fue reducido de seis semanas a un día, mientras que la pena máxima continuó siendo seis meses. La pérdida de los derechos civiles podía resultar en la pérdida del título de Doctor o en la prohibición de participar en las elecciones.

\section{Marx y Engels: ¿homófobos?}

Los fundadores del marxismo han sido acusados de homofobia en un artículo sobre Johann Baptist von Schweitzer cuyo autor describe a Schweitzer como "el queer que Marx amaba odiar" (Kennedy 1995). ${ }^{3}$ Además de la afirmación gratuita de que Marx intentó inducir a Engels a hacer circular chistes homofóbicos en torno a Schweitzer con el fin de manchar su nombre, en una carta fechada el 10 de marzo de $1865^{4}$ (tres años después que Schweitzer fuera arrestado, en mayo de 1862, en un parque de Mannheim, por tener relaciones homosexuales con un adolescente), la principal prueba que aduce el autor del artículo para acusar a Marx y Engels de homofobia es una carta de Engels a Marx, fechada el 22 de junio de 1869, que dice lo siguiente:

El Urning que me enviaste es una cosa muy curiosa, son revelaciones extremadamente antinaturales; los pederastas comienzan a ponerse en contacto y descubren que son un poder en el estado. Sólo carecían de organización, pero según esta fuente, al parecer ya existe en secreto. Y puesto que tienen hombres tan importantes en todos los viejos partidos e incluso en los nuevos, de [Johannes] Rösing a Schweitzer, no pueden dejar de triunfar. "Guerre aux cons, paix aux trous-de-cul"5 será ahora el eslogan. Es una suerte que nosotros, personalmente, seamos demasiado viejos para temer, cuando este partido gane, que tengamos que pagar un tributo físico a los vencedores. ¡Pero la generación más joven! Sólo en Alemania un sujeto como éste puede presentarse, convertir esta porquería en una teoría y ofrecer la invitación: introite (entren), etc. Lamentablemente, todavía no ha reunido el coraje para reconocer públicamente que es "eso" ("Das"), y debe seguir operando coram publico (públicamente) "de frente" ("von vorn"), si bien no "por adelante" ("von vorn hinein"), como dice por accidente una vez. Pero espera a que el nuevo Código Penal de la Confederación Alemana del Norte reconozca los "droits du cul" ("derechos del culo"), y entonces operará de manera muy diferente. Y a nosotros pobre gente "de frente", con nuestra pasión infantil por las mujeres, nos irá entonces bastante mal. Si Schweitzer sirviera para algo, podría extraer de este pequeño burgués peculiar los detalles de los pederastas en los ámbitos más altos, lo cual no le resultaría difícil como espíritus afines que son. ${ }^{6}$

Engels no está aludiendo aquí a la teoría general de Karl Ulrichs sobre el "Urning" (su término para homosexual), sino al folleto específico que Marx le envió titulado, Incubus: amor uranio y sed de sangre (Ulrichs 1869), como lo reconoce el propio Kennedy, ya que Ulrichs nunca escribió una obra titulada simplemente Uming (en otras palabras, Engels reporta el título equivocadamente). ${ }^{7}$ El folleto Incubus,

\footnotetext{
${ }^{3}$ Kennedy, quien se autodefine como anarquista, es también autor de una biografía celebratoria de Karl Heinrich Ulrichs (Kennedy 2002).

${ }_{4}^{4}$ Marx an Engels in Manchester, [London] 10 March [1865], en Karl Marx und Friedrich Engels, Werke, Berlin: Dietz-Verlag, 1965, Band 31, p. 96.

5 "Guerra a las conchas, paz a los agujeros de culo", un perífrasis del lema de la revolución francesa "Guerre aux chateaux, paix aux chaumières!": "Guerra a los palacios, paz a las chozas!"

${ }^{6}$ Engels an Marx in London, Manchester, 22. Juni 1869, en Karl Marx und Friedrich Engels, Werke, Berlin: Dietz-Verlag, 1973, Band 32, p. 324-325.

${ }^{7}$ El folleto que Marx envió a Engels fue identificado por los editores de Marx Engels Werke como Argonauticus de Ulrichs. Pero esto no puede ser correcto, ya que Argonauticus no se completó hasta finales de septiembre de 1869. La referencia a "introite" sugiere algún conocimiento del Memnon de Ulrichs (1868), porque dicha frase aparece en el epígrafe de ese folleto: "jIntroite! Nam et hoc templum naturae est" (“iEntren! Porque este es también un templo de la naturaleza”). El folleto que Engels leyó fue Incubus, que se completó el 4 de mayo de 1869. Esto es confirmado por varias indicaciones, la más importante de las cuales es el uso de Ulrichs de "von vorn binein" en lugar de "von vorn herein" que Engels menciona en su retruécano y que ocurre dos veces en Incubus (la frase idiomática "von vorn berein" significa "desde el principio"). En su obra en Memnon, Ulrichs varias veces se refiere a sí
} 
Urningsliebe und Blutgier es un intento de explicar las causas que llevan a ciertos hombres a cometer violaciones y asesinatos de niños. El incidente particular que indujo a su escritura es el caso del teniente del ejército prusiano Carl von Zastrow, quién, en enero de 1869, fue acusado de violar y asesinar brutalmente a un niño de cinco años llamado Emil Hanke. Ulrichs, quien dejaba en claro que no estaba defendiendo los actos de violación infantil y pederastia acompañados de asesinatos, hacía sin embargo una súplica de piedad para tales criminales sobre la base de que se comportaban de esa manera no por malicia, sino más bien por una "disposición natural defectuosa" (fehlerbafte Naturanlagen) o "una naturaleza enferma" (krankhafte Gemütsaffection) como lo llama alternativamente (Ulrichs 1869, pp. 37, 39).

El trabajo intenta usar los argumentos de los estudios anteriores de Ulrichs sobre el varón uranio (gay) como producto de una disposición natural que hace que se sientan atraído hacia personas de su mismo sexo para probar que los pederastas violentos no deben ser tratados como criminales sino como personas espiritualmente enfermas, que no pueden controlar la naturaleza innata de su sexualidad más que un uranio o que un "dionio" (Dioning), o sea un heterosexual. Según Ulrichs: "El caso Zastrow está en estrecha relación con la naturaleza sexual del Urning que ama a los hombres" (Der zastrow'sche Fall stebt in engster Beziehung zur Geschlechtsnatur des mannliebenden Urnings) porque "a veces hay un anhelo, un deseo salvaje y desordenado en ciertas personas de cometer crueldades y de ver fluir la sangre sin una razón clara, una sed de sangre que, según parece, va mucho más allá de un estado mental responsable, que en el momento en que se hace presente parece presionar fuertemente sobre el alma del individuo como un íncubo que se levanta del reino de la oscuridad" (Ulrichs 1869, pp. 75, 49).

En el curso de su análisis, Ulrichs describió quince casos de "perversión" sexual además del caso Zastrow, muchos de los cuales involucraban a hombres mayores de alto rango en la sociedad alemana. El folleto es de lectura muy difícil. Ulrichs, por ejemplo, describe en detalle cómo Zastrow violó, castró y golpeó a Emil Hanke, y más tarde cómo violó, golpeó, sodomizó con un palo y luego asesinó a un chico de 15 años. Los otros quince casos son de una brutalidad similar y contienen descripciones gráficas parecidas. De hecho, Ulrichs quiere resaltar la brutalidad de estos casos para demostrar su hipótesis de que su carácter era incontrolable. Por lo tanto, argumentaba, los tribunales no deben castigar a estas personas, sino más bien buscar otros medios para frenar este comportamiento. Es por estos motivos que Engels describió la obra como algo "muy curioso" que implicaba "revelaciones extremadamente antinaturales". Engels no estaba comentando aquí sobre la homosexualidad en general, ni sobre la militancia del Ulrichs a favor de la despenalización de la homosexualidad ${ }^{8}$, sino sobre los fenómenos de pederastia violenta descritos en Incubus.

El movimiento alemán por los derechos de los homosexuales floreció recién en las décadas de 1870 y 1880. La idea de que existen personas "homosexuales" y "heterosexuales" fue presentada por primera vez en 1869 por Karl-Maria Kertbeny, un periodista húngaro nacido en Austria, y el término mismo recién alcanzó popularidad en la década de 1880. Esto explica la falta de referencias al tema de la despenalización de la homosexualidad en las obras de Marx y Engels, y el hecho de que dicha demanda fuera defendida recién por sus discípulos dentro del movimiento obrero alemán, quienes en 1865 fundaron lo que pasaría a ser conocido en 1890 como el Partido Socialdemócrata de Alemania (Sozialdemokratische Partei Deutschlands, SPD).

mismo como un ejemplo de un Urning, pero no en Incubus. Johannes Rösing, un comerciante de Bremen que estuvo activo en el movimiento democrático en Alemania en las décadas de 1830 y 1840, fue mencionado en Incubus, pero Engels podría haber sabido de él por otras fuentes.

${ }^{8}$ En 1865, Ulrichs presentó una petición en el Día de los Abogados alemanes para abolir las disposiciones penales contra la homosexualidad masculina, que fue rechazada. En la reunión del Día del Jurista el 29 de agosto de 1867 en Munich, Ulrichs exigió públicamente la abolición de todos los párrafos contra los "Urninge" (homosexuales) frente a 500 oyentes, pero se le impidió finalizar su discurso ante la fuerte protesta de los abogados presentes. Posteriormente Ulrichs dirigió al gobierno numerosas peticiones para despenalizar la homosexualidad, que fueron desatendidas. 


\section{Los marxistas alemanes y la lucha por la eliminación del párrafo 175 del Código Penal}

En 1895, el dirigente de la Socialdemocracia alemana Eduard Bernstein escribió un artículo sobre el juicio a Oscar Wilde, titulado "Con motivo de un proceso sensacional", en el que juzgó muy ásperamente su obra literaria, a la que veía como propia de un epígono de los decadentistas franceses, y su doctrina del arte por el arte, que consideraba frívola y estéril. En cuanto al proceso mismo, Bernstein consideraba que "el amor masculino (Männerliebe), como las anormalidades del comportamiento sexual en general, ha existido entre los más diversos pueblos y en niveles muy diferentes de desarrollo cultural, y no se pueden sacar conclusiones sobre la viabilidad de una sociedad en su conjunto a partir de casos aislados de este tipo" (Bernstein 1895a, p. 176).

En una secuela al artículo sobre el juicio a Oscar Wilde, titulado "La evaluación de las relaciones sexuales anormales", Bernstein aclaraba que utilizaba la expresión "relaciones sexuales anormales" (widernormalen Geschlechtsverkehrs) en lugar de la expresión "antinaturales" (widernatürlich), porque ésta última inducía al error. Bernstein se preguntaba "¿qué no es antinatural? Toda nuestra existencia cultural, nuestro modo de vida desde la mañana hasta la noche es una ofensa constante contra la naturaleza, contra las precondiciones originales de nuestra existencia. Si fuera sólo una cuestión de lo que es natural, entonces el peor exceso sexual no sería más objetable que, por ejemplo, escribir una carta: mantener una relación social a través de la palabra escrita está mucho más alejado de la naturaleza que cualquier forma conocida de satisfacer el impulso sexual" (Bernstein 1895b, p. 229). A la observación de aquellos que señalaba que las relaciones sexuales normales eran las que conducían a la procreación y a la reproducción de la especie, Bernstein respondía "que, en la práctica, las relaciones sexuales [entre personas heterosexuales] se llevan a cabo por puro placer y, puesto que se han emancipado de la procreación, son no solamente antinaturales, sino también anormales" (Bernstein 1895b, p. 230).

Bernstein concluía que "las relaciones sexuales anormales son tan antiguas y tan extendidas, y las encontramos en niveles culturales tan diversos, que no se puede decir con certeza que estuvieron ausentes en ninguna etapa del desarrollo cultural humano. Del mismo modo, la teoría frecuentemente repetida que atribuye exclusivamente la ocurrencia más frecuente de relaciones sexuales anormales a los llamados tiempos de decadencia no puede sostenerse". El autor daba como ejemplo la práctica de la pederastia en la Atenas clásica (Bernstein 1895b, p. 231). Bernstein también señalaba que, mientras que la práctica del amor homosexual femenino había sido ignorada en la mayoría de los lugares y en la mayoría de las épocas, las relaciones homosexuales entre los miembros del sexo masculino habían sido penalizadas repetidas veces a lo largo de la historia, un hecho que atribuía paradójicamente a la opresión de la mujer: "la libertad otorgada al cuerpo femenino refleja el desprecio (Nichtachtung, Geringschätzung) hacia la mujer, que comenzó con el surgimiento de la familia por derecho paterno". La hipocresía de la moral prevaleciente era revelada por el hecho de que "lo que ocurre a diario en los burdeles y prostíbulos bajo la mirada de la policía es declarado menos pernicioso para las normas morales que la participación en el amor masculino" (Bernstein 1895b, p. 232).

\section{El primer intento de Hirschfeld y el SPD de despenalizar la homosexualidad (1898)}

El Comité Científico Humanitario (Wissenschaftlich-bumanitäres Komitee), liderado por Magnus Hirschfeld, fue fundado en Berlín en mayo de 1897 y en diciembre del mismo año redactó una petición, firmada por más de 800 personas, para despenalizar la homosexualidad eliminando el párrafo 175 del Código Penal Alemán. ${ }^{9}$ En sus memorias Hirschfeld recordaba haber conocido personalmente a Bebel y

9 Thiele 1909a, p. 1490. La mejor biografía de Magnus Hirschfeld es Herzer 2017. Sobre la polémica en torno al párrafo 17 del Código Penal durante el Segundo Imperio alemán ver Taeger und Lautmann 1992. 
a otros socialdemócratas destacados durante sus estudios en Múnich y Berlín: "Mi propio desarrollo intelectual me puso en contacto personal con los líderes de la Socialdemocracia alemana de entonces, August Bebel y Wilhelm Liebknecht en Berlín, y Georg von Vollmar y Ludwig Viereck en Múnich" (Hirschfeld 1930, p. 81). Su padre había sido un "Achtundvierziger" -es decir, un participante en las revoluciones de 1848- y de él había heredado fuertes tradiciones democráticas que lo acercaron al Partido Socialdemócrata. Hirschfeld también recordaba que "ya a la edad de veinte años", es decir, poco después de su graduación como médico, se familiarizó con los puntos de vista socialdemócratas leyendo el libro de August Bebel La mujer y el socialismo. Hirschfeld se suscribió el 1 de enero de 1891 al Vorwärts, el periódico del Partido Socialdemócrata, pero nunca aclaró cuándo se unió al SPD (Herzer 2017, p. 34).

El 13 de enero de 1898 August Bebel, un obrero tornero y líder del Partido Socialdemócrata de Alemania, pronunció un famoso discurso en el Reichstag apoyando la petición. ${ }^{10}$ Hirschfeld pensaba que el motivo que había llevado a Bebel a apoyar la petición era que su predecesor en la dirección editorial de Vorwärts, el sucesor de a Ferdinand Lassalle como presidente de la Asociación General de Trabajadores Alemanes, Johann Baptist von Schweitzer, había sido sentenciado a una pena de prisión en 1862 en Mannheim por tener relaciones homosexuales con un albañil (Herzer 2017, p. 75).

En su discurso ante el Reichstag, Bebel afirmó que, a pesar de que las disposiciones del Párrafo 175 eran "sistemáticamente violadas por un gran número de personas, tanto hombres como mujeres, únicamente en los casos más raros la policía se molesta en requerir acciones por parte del fiscal". La policía de Berlín no llevaba ante el Fiscal de Distrito los nombres de los hombres que cometían delitos punibles con encarcelamiento según el párrafo 175, sino que, al tener conocimiento del hecho, más bien agregaban los nombres de las personas involucradas a la lista de aquellos que, por las mismas razones, aparecían ya en sus archivos. Según Bebel, "la cantidad de estas personas es tan grande y llega tan lejos en todos los niveles de la sociedad que, si la policía aquí llevara a cabo escrupulosamente su deber, el Estado Prusiano se vería inmediatamente obligado a construir dos nuevas penitenciarías tan solo para ocuparse de aquellos que, solamente en Berlín, han cometido delitos contra el párrafo 175." Se trataba "de miles de personas de todos los ámbitos... quizás esta sea una de las razones por las cuales las ofensas cometidas bajo este Párrafo son tratadas de manera tan extraordinariamente laxa por parte de la policía." Además, "lo que es justo en el caso de un sexo, lo es igualmente para el otro", pero el Código Penal alemán penalizaba solamente la homosexualidad masculina, no la femenina.

Bebel concluía afirmando que, si el párrafo 175 del Código Penal no podía ser aplicado, o podía ser aplicado sólo selectivamente, no debía ser conservado. A tal fin, agregaba, "tenemos ante nosotros una petición impresa, firmada entre otros por mí personalmente, y por un número de colegas de otros partidos, además de miembros de círculos literarios y académicos, juristas de gran renombre, psicólogos y patólogos y expertos del más alto rango en este campo. La petición, sobre la que, por razones entendibles, no quiero entrar en detalles en este momento, exige una revisión del Código Penal en este campo, en el sentido de lograr la derogación de las disposiciones relevantes del párrafo 175". ${ }^{11}$

La petición del Comité-Científico Humanitario contra el párrafo 175 fue rechazada en comisión por el Reichstag. Hirschfeld, sin embargo, consideró el mero hecho de que el parlamento discutiera la cuestión en 1898 como una señal de progreso; de hecho, fue suficiente para convencerlo de que "la vérité est en marche" (Hirschfeld 1899, p. 297, la cita de Zola termina diciendo: "et rien ne l'arrêtera"). En un artículo aparecido en el primer número de la revista del Comité-Científico Humanitario, el Jahrbuch für sexuelle Zwischenstufen (Anuario para los estadios sexuales intermedios), Hirschfeld reprodujo la petición en pp. 239-241,

\footnotetext{
10 Es interesante que Bebel haya suscrito la petición a pesar de haber apoyado originalmente el punto de vista, ya refutado por Bernstein, según el cual la homosexualidad masculina estaba ligada a la decadencia de las clases dominantes: "El número de libertinos jóvenes y viejos es enorme, y tienen necesidad de estímulos especiales, porque están embotados y saturados por el exceso. Muchos, por lo tanto, caen en las antinaturalidades de la era griega. La homosexualidad masculina (Die Männerliebe) es mucho más común hoy de lo que la mayoría de nosotros imaginamos." (Bebel 1898, p. 200)

11 Reichstagsprotokolle, 1897/98, 1. 16. Sitzung. Donnerstag den 13. Januar 1898, p. 410.

http://www.reichstagsprotokolle.de/Blatt k9 bsb00002771 00462.html
} 
seguida de la lista de firmas y de un apéndice a la petición, que aparece en pp. 266-269. Hirschfeld reprodujo también el discurso de Bebel del 13 de enero de 1898, así como dos intervenciones más de Bebel en el Reichstag a favor de la despenalización de la homosexualidad (Hirschfeld 1899, pp. 272-279).

\section{El tratamiento de la homosexualidad en la revista Die neue Zeit}

Karl Kautsky, el editor de la revista teórica del ala "ortodoxa" del Partido Socialdemócrata de Alemania, Die neue Zeit, había sido unos de los firmantes originales de la petición del Comité CientíficoHumanitario de Hirschfeld. En un artículo muy interesante sobre la homosexualidad y el párrafo 175 del Código Penal, publicado en 1898 en Die neue Zeit, el órgano teórico del ala "ortodoxa" del SPD (para entonces Bernstein había comenzado su famosa "revisión" reformista del marxismo), el autor, W. Herzen, reportaba que en la sesión del 18 de enero de 1898 del parlamento alemán, el pastor Martin Schall, un diputado en el Reichstag, se declaró "consternado y deprimido" por la iniciativa de Bebel de abolir el párrafo 175 del Código Penal alemán, que había sido suscrita por "hombres con nombres famosos de todas las profesiones" (Herzen 1898, p. 555). Según el autor del artículo, Herzen, la opinión pública se ocupaba de la "cuestión homosexual" (bomosexuelle Frage) sólo de tanto en tanto, particularmente en ocasión de algunos "procesos judiciales sensacionales" como el juicio a Oscar Wilde, pero sólo a fin de encubrir todo aquello que fuera contrario a la "moral corriente en cuestiones sexuales". Lo que se discutía en estas cuestiones correspondía en consecuencia a la hipocresía reinante, que buscaba "impedir, mediante algún tipo de reglamentación legal, que estas cosas se manifiesten públicamente." Sólo entonces "el burgués honesto se siente tranquilo", a pesar de que el párrafo 175 era insostenible "desde el punto de vista médico, jurídico y ético."

La medicina había comenzado a ocuparse de la cuestión homosexual en los años 50 del siglo XIX. En ese entonces, las leyes de los distintos estados alemanes consideraban a los Urning (homosexuales) como criminales, mientras que la medicina los incluía en la categoría de enfermos mentales. El autor mencionaba para refutar esta concepción al trabajo de Magnus Hirschfeld, $\int 175$ des Reichsstrafgesetzbuch. Die homosexuelle Frage im Urteile der Zeitgenossen (Leipzig: Spohr, 1898), sobre el cual decía lo siguiente: "En este escrito se reúnen las respuestas que el redactor de la petición, el Dr. Hirschfeld, ofreció en la fundamentación para su aprobación. Refuta las objeciones de los oponentes a la petición, en la medida en que éstas son aparentes a partir de las respuestas, de modo que este folleto puede ser considerado como la justificación de la petición" (Herzen 1898, p. 556, nota 3). El autor mencionaba la "ocurrencia tremendamente común del amor homosexual", y agregaba que en el sexo femenino era "no menos común" (Herzen 1898, p. 556). Citaba la estimación de Ulrichs según la cual uno de cada 200 hombres era homosexual, lo que arrojaba un total para Alemania de entre 50.000 y 60.000 "Uminge". También mencionaba la constatación de Hirschfeld de que la homosexualidad podía ser encontrada "en todas las razas y en todas las naciones de la tierra, tanto en las capas más altas como en las más bajas de la población, en las ciudades y en el campo, entre personas educadas y no educadas, honradas y deshonestas" (Hirschfeld, $\int 175$ des Reichsstrafgesetzbuch, p. 43), y enumeraba a algunas famosas figuras históricas como "Sófocles, Sócrates, Alejandro el Grande, Julio César, Virgilio, Michelangelo, Shakespeare, Molière", etc. (Herzen 1898, p. 557). Citaba la afirmación de Schopenhauer según la cual extensión geográfica y temporal del amor entre personas del mismo sexo probaba que debía tener su origen en la naturaleza humana (Herzen 1898, p. 557). Luego intentaba justificar esta posición por referencia a la "embriología (conjuntamente con la filogenia y la antropología)", basándose en el trabajo de Magnus Hirschfeld, publicado bajo el seudónimo “Th. Ramien”, Sappho und Sokrates: oder wie erklärt sich die Liebe der Männer und Frauen zu Personen des eigenen Geschlechts? (Leipzig: Verlag von Max Spohr, 1896).

Luego de esta "incursión en la medicina", el autor pasaba a afirmar que "también desde el punto de vista jurídico el párrafo 175 es un sinsentido" porque "la expresión 'antinatural' es totalmente errónea y falsa", como lo había demostrado el "artículo de Bernstein sobre este tema" en Die neue Zeit, el cual también probaba "en forma absolutamente acertada, por qué motivo el amor homosexual es penalizado 
en la mayoría de los países (con excepción de Austria) sólo entre hombres” (Herzen 1898, p. 559). El párrafo 175 transformaba en delito un acto en el cual no se lesionaban los derechos de nadie. Por ese motivo el amor homosexual había sido despenalizado en Francia ya en 1791, en Italia, Bélgica, Holanda, y en toda una serie de estados alemanes. En respuesta a la afirmación de que la "opinión pública" (Volksbewnsstsein) exigía la retención del párrafo 175, el autor recordaba que también la quema de brujas había sido justificada por motivos similares, en respuesta a los críticos contemporáneos que afirmaban que dichos procesos carecían de todo fundamento (Herzen 1898, p. 559).

Siguiendo la argumentación de Hirschfeld, Herzen afirmaba que el amor homosexual era el resultado de un poderoso impulso natural, y que por ende su penalización no podía arrojar resultado alguno, ni desde el punto de vista de la "rehabilitación" del imputado ni desde el punto de vista de la “disuasión". En Berlín existía una comunidad homosexual extensa y activa, con sus lugares de encuentro y sus actividades, incluyendo locales en los que se practicaba la prostitución masculina (Herzen 1898, p. 560). El autor citaba el discurso de Bebel en el Reichstag del 13 de enero de 1898, en el que se afirmaba que la revelación de la extensión de la homosexualidad en los altos círculos de la sociedad y del gobierno hubiera generado un escándalo superior al del canal de Panamá. La legislación existente sólo promovía el chantaje y la extorsión en los círculos criminales (Herzen 1898, p. 560). El autor concluía afirmando que "el amor homosexual debe ser totalmente equiparado al amor heterosexual también en el Código Penal. Esta demanda es el meollo de la petición. La empresa en la que el redactor y los primeros signatarios de la petición (Bebel, Wildenbruch, Krafft-Ebing y Franz von Liszt) se han embarcado es una iniciativa meritoria y valiente" (Herzen 1898, p. 561).

Una reseña publicada en Die neue Zeit de los dos primero tomos del quinto número de la revista del Comité Científico-Humanitario, Jabrbuch für sexuelle Zwischenstufen unter besonderer Berücksichtigung der Homosexualität, alababa el artículo de Magnus Hirschfeld sobre "Las causas y la esencia del uranismo", en particular "el capítulo sobre la necesidad natural de la homosexualidad", y describía brevemente el resto de sus contenidos, incluyendo una carta de Goethe sobre el amor homosexual en Roma y un estudio "sumamente interesante" del Dr. Römer "Sobre la idea andrógina de la vida", concluyendo: "Ojalá que el nuevo número de esta publicación encuentre muchos lectores" (Herzberg 1900, p. 124).

Otra reseña de la revista editada por Magnus Hirschfeld, publicada en Die neue Zeit cuatro años más tarde, indicaba que era una publicación del Comité Científico-Humanitario que había comenzado a aparecer en Berlín y Leipzig en mayo de 1897, con el objetivo de conseguir la abolición del párrafo 175 del Código Penal Imperial. Su objetivo era, por ende, doble: el esclarecimiento científico de la situación de los homosexuales, una categoría de personas consideradas como criminales o enfermos mentales, pero que en realidad debían ser consideradas solamente como personas con un impulso sexual diferente, y la agitación contra una legislación que transformaba un impulso natural en un delito. Luego pasaba a reseñar los artículos del número reciente de la revista: el de Magnus Hirschfeld sobre "El diagnóstico objetivo de la homosexualidad", "Cuatro cartas de Karl Heinrich Ulrichs (Numa numantius) a sus semejantes" (cuyos escritos eran descritos como "los fundamentos para todos los estudios posteriores sobre el tema"), dos artículos sobre el estatus jurídico de la homosexualidad y uno sobre su psicología, una extensa "bibliografía sobre la homosexualidad" y, finalmente, la petición presentada en el Reichstag por el Comité (Fuchs 1904).

\section{El “caso Krupp” en 1902}

Las relaciones entre el Comité Científico-Humanitario y el SPD experimentaron cierta fricción en 1902, con el estallido del escándalo en torno a la homosexualidad del magnate del acero Friedrich Alfred Krupp, quien vivía en la isla italiana de Capri varios meses al año. Los lugareños de Capri sabían que Krupp era homosexual, que tenía una serie de relaciones con jóvenes locales, y circulaban además historias sobre orgías homosexuales. Cuando estas historias comenzaron a aparecer en la prensa local, Krupp regresó a Alemania, esperando que las aguas se calmaran, pero nunca lo hicieron. Se siguieron 
publicando artículos en periódicos italianos que mencionaban a un gran industrial alemán y la noticia finalmente llegó a Alemania el 8 de noviembre de 1902, cuando el periódico del Partido del Centro católico Augsburger Postzeitung citó informes al respecto de dos periódicos italianos, sin indicar el nombre del personaje involucrado.

El 15 de noviembre de 1902, el periódico socialdemócrata Vorwärts hizo público en Alemania el nombre de Krupp en un artículo titulado "Krupp en Capri". El artículo, al mismo tiempo que revelaba la identidad homosexual de Krupp, denunciaba en cinco ocasiones al párrafo 175 del Código Penal. Así afirmaba, por ejemplo, que "el caso debe ser discutido en público, con la necesaria precaución, ya que puede proporcionar el ímpetu necesario para finalmente eliminar del Código Penal alemán el párrafo 175, que no sólo castiga al vicio (Laster) sino que también condena la desafortunada predisposición de personas moralmente sensibles a un temor constante y las coloca ante la amenaza continua de caer en prisión o ser víctimas de chantajes".

Luego el artículo del Vorwärts desarrollaba el argumento de que el párrafo 175 del Código Penal no sólo era injusto en sí, sino que era doblemente injusto porque no se aplicaba a los miembros de las clases dominantes. Afirmaba, a contramano de la prensa burguesa alemana, que "Krupp no eligió Capri para proveer a los lugareños de caminos, sino porque el Código Penal italiano no posee ningún párrafo 175 " -es decir, porque la homosexualidad no estaba penalizada en Italia. El artículo concluía afirmando: "Mientras Krupp continúe viviendo en Alemania, está sujeto a las penas que estipula el párrafo 175 del Código Penal. Cuando la perversidad conduce a un escándalo público, el estado debe intervenir inmediatamente. Esperemos que el público reflexione ahora sobre la necesidad de eliminar esta contradicción entre la ley y la aplicación del derecho, que hiere el sentido de la justicia, y sobre la necesidad de eliminar el párrafo 175, que no erradica el vicio, pero agudiza el dolor del infortunio. La Socialdemocracia ha insistido repetidas veces en el Reichstag sobre la necesidad de dicha reforma."12

Krupp envió el día mismo de la publicación un telegrama al fiscal del tribunal de distrito nro. I de Berlín solicitando el procesamiento del Vorwärts por difamación, lo que hizo que el número fuera confiscado por la policía. Toda la prensa alemana comentó sobre estos eventos; varios otros periódicos en Dortmund, Dusseldorf, Hanover, etc. fueron procesados por la reimpresión del artículo y búsquedas domiciliarias se llevaron a cabo en sus oficinas editoriales. La prensa burguesa se preguntaba si las acusaciones del Vorwärts estaban basadas en la verdad o si había actuado "por motivos anticapitalistas", para dejar en claro, sobre la base de un "caso ejemplar", la insostenibilidad del párrafo 175. En medio del escándalo, el 22 de noviembre de 1902, se difundió la noticia de la muerte de Krupp. La oficina oficial de telégrafos la anunció de la siguiente forma: "Villa Hügel, 22 de noviembre. Su Excelencia Krupp murió esta tarde a las 3 en punto. La muerte ocurrió como resultado de un accidente cerebrovascular que tuvo lugar 6 horas antes." (Hirschfeld 1903, pp. 1310-1310).

El día de la noticia de la muerte de Krupp, el 22 de noviembre de 1902, Hirschfeld escribió una carta a Kurt Eisner, el editor en jefe del Vorwärts, en la que reafirmó, entre otras cosas, su concepción no patológica de la homosexualidad en las siguientes palabras:

¡Estimado Sr. Eisner! Acabo de recibir la noticia de la muerte de Krupp. Puedo suponer que va a ser presentado como una víctima del párrafo 175, lo que sin duda fue, es decir, una de las muchas víctimas [...] El objetivo principal de estas líneas es informarle que, como he oído de una fuente confiable, Krupp se había hecho hipnotizar hace años con un médico de Berlín debido a su condición. Por supuesto, el tratamiento no tuvo éxito, ya que [la homosexualidad] no es en absoluto una enfermedad, sino que se trata de una predisposición particular innata, una transición espiritual, una etapa intermedia entre los hombres y las mujeres. ${ }^{13}$

12 "Krupp auf Capri”, Vorwärts, 15. November 1902, pp. 2-3.

13 La carta se conserva en el „Archiv der sozialen Demokratie der Friedrich-Ebert-Stiftung“, Bonn, Signatur: Mikrofilme Moskau, Fonds 212 Bd 43. Citada en Herzer 2017, p. 110. 
Inmediatamente después del anuncio de la muerte súbita de Krupp a los 48 años, la prensa expresó dudas sobre si las declaraciones oficiales acerca de su muerte eran ciertas. Estas dudas se intensificaron considerablemente cuando no se realizó una autopsia del cadáver. Al funeral, que tuvo lugar en Essen el 26 de noviembre de 1902, asistieron más de 20.000 personas, incluyendo los ministros de guerra, ferrocarriles, comercio, relaciones exteriores y marina, y, sobre todo, el Kaiser alemán, cuya corona llevaba la inscripción: "Mi mejor amigo. Wilhelm". En su discurso, el Kaiser atacó a "los hombres que quieren ser líderes de los obreros alemanes", acusándolos de ser responsables de la muerte de Krupp, "a quien la población obrera alemana tiene infinitamente tanto que agradecer", y expresando su deseo de que la clase obrera alemana pusiera fin a sus "vínculos con los autores de este acto vergonzoso" (Hirschfeld 1903, pp. 1311-1314).

En su respuesta al discurso del Kaiser, el Vorwärts enfatizó que el emperador "no podía haber leído el artículo, ya que fue confiscado," y que el periódico no había comenzado la discusión del caso Krupp por razones políticas, sino para fomentar "una reforma penal":

Queríamos demostrar, mediante el caso de un nombre particularmente bien conocido, la necesidad de derogar el párrafo 175, que para muchos desafortunados es un azote constante, que no sólo pone al vicio en manos de los chantajistas y de los jueces, sino que amenaza todo el tiempo con una catástrofe a un error de la naturaleza y, como ha sido científicamente demostrado, ha causado un terrible número de suicidios - la eliminación de una disposición legal que también ha resultado en una enorme contradicción entre la ley escrita y su aplicación, y que hace que el destino de numerosas personas esté sujeto a la voluntad de la policía. Por eso mencionamos el caso Krupp, por eso llamamos la atención sobre el hecho de que en Alemania esas personas están totalmente a merced de la arbitrariedad del párrafo 175. [...] Estamos en condiciones de mostrar en el juicio, que creemos que se llevará a cabo públicamente, pruebas convincentes de la pureza de nuestros motivos y de la verdadera intención de nuestra acción. [...] Y debido a que no tenemos la más mínima razón para dudar de la fiabilidad absoluta y de la imparcialidad de nuestros informantes, sacamos de esto la conclusión necesaria: si es cierto que el trágico final de Krupp está relacionado de alguna manera con los consabidos dos meses de publicaciones, entonces no fue víctima de una calumnia despiadada, sino una de las muchas víctimas del párrafo 175. (Hirschfeld 1903, pp. 13141316)

La referencia a los chantajistas probablemente se deba a la carta de Hirschfeld, porque en la misma, como en su informe anual publicado en su revista, afirmó que Krupp "también estaba en manos de chantajistas (Rhode)". 14

La viuda de Krupp inició una acción legal contra el Vorwärts, pero la abandonó el 15 de diciembre de 1902. El Vorwärts expresó su satisfacción por el fin de la demanda, afirmando: "compartimos los sentimientos de la viuda, y nos satisface humanamente que nos liberemos de la necesidad de llevar a un hombre muerto ante la justicia". Al mismo tiempo, insistió que "fue por el párrafo 175 que discutimos el caso Krupp. Los testimonios verdaderamente impactantes de personas que sufrieron el flagelo del párrafo 175 y que se acercaron a nosotros con motivo de nuestra publicación, han fortalecido aún más nuestra convicción de la necesidad de su eliminación o enmienda. Esperamos que, a pesar de la cancelación del juicio, el caso de Krupp no sea olvidado en la próxima revisión del Código Penal." (Citado Hirschfeld 1903, pp. 1316-1317).

En cuanto a las consecuencias políticas del caso Krupp, Hirschfeld creía que "el triste caso ha tenido consecuencias positivas, en el sentido de haber despertado y hecho reflexionar a una gran masa de

\footnotetext{
14 "Durante años, han circulado rumores que afirmaban que Krupp es homosexual, no sólo en círculos homosexuales, donde no se les habría dado mucha importancia, sino entre los chantajistas (caso Rhode)" (Hirschfeld 1903, p. 1304). En las memorias del comisionado criminal de la "sección de pederastas" de la policía de Berlín, Hans von Tresckow, Gustav Rhode fue descrito como "uno de los peores extorsionadores de Berlín". Rhode fue finalmente condenado a cinco años de prisión por varios actos de chantaje contra homosexuales. (Herzer 2017, p. 110)
} 
personas que eran indiferentes u hostiles a la cuestión homosexual. En muchos miles de artículos periodísticos, en numerosos folletos, se hizo referencia al párrafo 175, y debe señalarse notablemente que, con muy pocas excepciones, no ha habido ningún periódico ni partido, ni siquiera el Centro, que haya defendido el párrafo 175 o solicitado su retención." (Hirschfeld 1903, p. 1318).

En 1903, una editorial socialdemócrata publicó un folleto anónimo de 61 páginas sobre el caso Krupp, titulado Der Fall Krupp. Sein Verlauf und seine Folgen. Eine Tatsachensammlung (München: Druck und Verlag von G. Birk). Una reseña anónima de dicho panfleto apareció en el Jahrbuch für sexuelle Zwischenstufen, en la cual se afirmaba que el folleto, aunque ofrecía una exposición científica de la homosexualidad y exigía la eliminación del párrafo 175 del Código Penal, intentaba demostrar "que el artículo del Vorwärts apareció sólo por motivos nobles, a saber, denunciar la injusticia del párrafo 175, y que el Vorwärts casi se vio obligado a publicarlo", porque el resto de la prensa ya estaba haciendo alusión al caso. El autor de la reseña concluía afirmando:

Debe reconocerse que el Partido Socialdemócrata ha sido hasta ahora el único partido político que, como tal, se ocupó de la cuestión homosexual y exigió una reforma del párrafo 175.

Sin embargo, desde un punto de vista imparcial, no considero que el artículo sobre Krupp esté exento de objeciones, ya que la vida privada de Krupp, que no perjudicó al público, fue ampliamente publicitada y Krupp fue innecesariamente estigmatizado por su publicación en Alemania. También soy de la opinión de que el objetivo del Vorwärts no era simplemente probar la necesidad de derogar el párrafo 175, sino que tenía también un propósito político partidista -exponer a un importante representante del capitalismo- según lo sugerido por la forma y el contenido del artículo. Sin embargo, reconozco que la tentación de publicar los rumores de los periódicos italianos fue muy fuerte, y que el Vorwärts no merecía la tormenta de indignación que los periódicos de los otros partidos desataron sobre el órgano socialdemócrata.

La falta que el Vorwärts cometió en relación a Krupp ciertamente la habrían cometido los periódicos de las otras tendencias, especialmente los conservadores y los clericales, para con los líderes socialdemócratas, con la diferencia de que no habrían esperado tanto tiempo como el Vorwärts para lanzar contra ellos acusaciones que podían ser leídas en periódicos extranjeros. Sólo supongamos que Bebel o Singer hubieran tenido relaciones con jóvenes que pudieran despertar la sospecha de homosexualidad y que, en general, se los considerara homosexuales en el extranjero. ¿Los periódicos del Centro y los periódicos feudales no habrían crucificado a los líderes socialdemócratas, y no los habrían denunciado como ejemplos vivos de los efectos de sus doctrinas?15

\section{Nuevos intentos de Hirschfeld y el SPD de despenalizar la homosexualidad (1905-07)}

A pesar de que la petición del Comité Científico-Humanitario fue rechazada por el Reichstag en 1898, el interés en la cuestión había sido tan animado por la petición y los debates en el Reichstag que, después de que se celebraran nuevas elecciones al Reichstag en el verano de 1898, una segunda petición presentada por el Comité Científico-Humanitario alcanzó las 3.000 firmas. El documento llegó en la primavera de 1900 a una audiencia en la Comisión de Peticiones, justo después de que su presidente, el Dr. Kruse, hubiera muerto y, de que un diputado del Partido del Centro católico, Wattendorff, un oponente de la petición, tomara su lugar. La mayoría de la comisión, integrada por conservadores, ultramontanos, antisemitas y nacional-liberales, decidió declarar la petición inadecuada para el debate en el plenario. Todos los esfuerzos de parte de los socialdemócratas de que la petición se debatiera en el pleno del Reichstag resultaron en vano, aunque el diputado socialdemócrata Adolf Thiele reunió las 30 firmas de diputados que las reglas de procedimiento exigían para que la petición se debatiera en el pleno.

${ }^{15}$ Jabrbuch für sexuelle Zwischenstufen, VI. Jahrgang, 1904, pp. 457-460. 
Hasta el final del período legislativo en 1903, la petición para la eliminación o limitación del párrafo 175 fue inscrita en cada nueva lista de peticiones pendientes de tratamiento, pero no fue debatida.

Luego de la celebración de nuevas elecciones parlamentarias, la petición del Comité CientíficoHumanitario fue presentada nuevamente al Reichstag en el otoño de 1903, y el 20 de abril 1904 llegó a la Comisión de Peticiones. Fue presentada por el diputado del Partido del Centro católico, Johann Thaler de Würzburg, quien adoptó un punto de vista totalmente negativo, pero finalmente la Comisión decidió que la petición se discutiera en el pleno del Reichstag a insistencia de los 5 diputados socialdemócratas que la integraban. Sin embargo, pasó casi un año antes de que esto sucediera: no fue hasta el 31 de marzo de 1905 que la petición fue nuevamente discutida en el pleno del Reichstag (Thiele 1909a, pp. 1491-2).

Poco antes del debate sobre la petición en el Reichstag, un intento de asesinato causó un escándalo público y puso nuevamente sobre el tapete la cuestión de la despenalización dela homosexualidad. En enero de 1905, en la Hedwigskirche de Berlín, el director del tribunal de distrito de Breslau, Hasse, disparó contra un chantajista que había amenazado con revelar su homosexualidad. Según Magnus Hirschfeld, "De la prensa socialdemócrata, que de nuevo defendió unánimemente la eliminación del párrafo 175, se destacó el Königsberger Volkszeitung del 6 de enero de 1905, que entre otras cosas escribió:

Todos los intentos de eliminar el párrafo 175 del Código Penal han fracasado hasta ahora. Ya cuando dicho párrafo fue copiado del Código prusiano al Código Penal del Reich, la delegación científica decidió su eliminación, pero los oscurantistas en el Reichstag restauraron las amenazas de castigo, iqué les importa la ciencia! Ahora una nueva víctima de los prejuicios ha caído abruptamente de las alturas de la sociedad en circunstancias sensacionales. Tal vez el propio director del tribunal de distrito, Hasse, alguna vez tuvo que usar el arma terrible contra otros desafortunados, forzado por el Código Penal ihasta que el chantajista levantó su mano perversa para atacar! Ojalá que este caso sensacional contribuya finalmente a eliminar, en nombre de la justicia, un prejuicio que se cobra muchas víctimas cada año, que injustificadamente cataloga todo el tiempo a nuevas personas como criminales. No negamos nuestra compasión por el duro golpe. Tal vez él mismo alguna vez emitió duros juicios sobre nosotros y nuestros compañeros, no podemos decirlo por el momento, pero eso no nos impide considerarlo como la víctima inocente de una barbarie que gustosamente prestamos nuestra ayuda para erradicar. (citado en Hirschfeld 1905a, p. 967).

El informe sobre la petición del Comité Científico-Humanitario, que había sido firmada por más de 5.000 personas, fue presentado en el pleno del Reichstag por el diputado socialdemócrata Adolf Thiele y reproducido en la revista editada por Hirschfeld. ${ }^{16}$

En su informe sobre "la cuestión de la homosexualidad y de la bisexualidad" (die Frage der Homosexualität und der Bisexualität), Thiele señaló que "tratar de juzgar tal cuestión desde el punto de vista de la mera moral, de la tradición, recuerda la época de la Edad Media, la época en que las brujas eran quemadas, los herejes eran torturados y la horca era utilizada contra los que pensaban diferente" (Hirschfeld 1905b, pp. 972, 974). Thiele puntualizaba que la petición no exigía la eliminación del párrafo 175 sino su modificación, en el sentido de que las relaciones homosexuales serían penalizadas sólo "si se llevan a cabo por la fuerza o con personas menores de 16 años o de una manera que constituya un 'escándalo público" (Hirschfeld 1905b, pp. 976). Luego de señalar el absurdo de que el párrafo 175 penalizara las relaciones homosexuales entre hombres, pero no entre mujeres, Thiele señalaba que la

16 Adolf Thiele (1853-1925), nacido en 1853 en Dresde, trabajó como maestro de escuela primaria en Sajonia y en el distrito agrícola de Wurzen. En 1887 renunció a la docencia para dedicarse al periodismo y a la militancia política. De 1894 a 1908 fue editor del periódico Freie Volksblatt en Halle, actividad por la que pasó un total de 33 meses de prisión. De 1888 a 1892 Thiele fue concejal de la ciudad de Wurzen y de 1903 a 1912 de Halle. De 1898 a 1907 y de 1912 a 1918 fue también diputado del Reichstag por el distrito electoral de Liegnitz 8 en Naumburg (Saale). Con el estallido de la controversia revisionista en 1898, Thiele apoyó al ala revisionista y publicó artículos en la revista editada por Eduard Bernstein, Soz̧ialistische Monatshefte. Luego de la escisión entre el SPD y el USPD en 1917, Thiele permaneció en el Partido Socialdemócrata y en 1919 fue diputado por el mismo en la Asamblea Nacional que redactó la constitución de la república de Weimar. 
despenalización de la homosexualidad era la norma hacía ya mucho tiempo en "Francia, Holanda, etc." (Hirschfeld 1905b, pp. 978-979).

Thiele, siguiendo la tesis de Hirschfeld, afirmaba: "La ciencia ha reconocido que no sólo hay individuos masculinos y femeninos entre los humanos, como entre todos los demás seres vivos, sino que también hay un gran número de estadios intermedios, en los que ni el sexo masculino ni el femenino predominan. En el aspecto fisiológico esto es reconocido; pero no se quieren sacar las consecuencias necesarias en la vida emocional y sexual. Es bien sabido que existen bastantes estadios psicológicos o fisiológicos intermedios" (Hirschfeld 1905b, p. 980). Recordando la frase atribuida a Diógenes "naturalia non sunt turpia" ("Las cosas naturales no son vergonzosas"), Thiele sostuvo que, aunque no compartía la teoría de Hirschfeld acerca de la existencia de un tercer sexo ${ }^{17}$, "indudablemente, es el mérito del Comité Científico-Humanitario el haber lanzado enfáticamente al debate público este aspecto psicológico de la cuestión homosexual" (Hirschfeld 1905, p. 981). Thiele extraía como conclusión de las investigaciones del Comité Científico-Humanitario la idea de que "la disposición natural que obliga a algunas personas a la homosexualidad, de acuerdo con las investigaciones, es tal que con ella cesa el libre albedrío, y no tenemos derecho a exigir a estas personas que se vean forzadas a renunciar a la operación de esta disposición natural.” (Hirschfeld 1905, p. 994)

Thiele pasó entonces a detallar los resultados de las tres encuestas llevadas a cabo por el Comité Científico-Humanitario sobre la cuestión de la homosexualidad, entre los estudiantes de la Technische Hochschule de Charlottenburg, en Ámsterdam y entre los trabajadores metalúrgicos de Alemania. En el formulario de la encuesta, que era voluntaria y anónima, el informante debía consignar si era homosexual, heterosexual o bisexual. La encuesta arrojó los siguientes resultados: los heterosexuales constituían el 94\% entre los estudiantes de la Technische Hochschule de Charlottenburg, el 94,1\% entre los habitantes de Ámsterdam y el 95,7\% entre los trabajadores metalúrgicos. Los homosexuales y bisexuales constituían el 6\% entre los estudiantes de la Technische Hochschule de Charlottenburg, el 5,8\% entre los habitantes de Ámsterdam y el 4,3\% entre los trabajadores metalúrgicos, mientras que los homosexuales constituían el 1,5\% entre los estudiantes de la Technische Hochschule de Charlottenburg, el 1,9\% entre los habitantes de Ámsterdam, y el 1,1\% entre los trabajadores metalúrgicos. Es decir, las tres encuestas arrojaban porcentajes muy similares (Hirschfeld 1905, p. 982).

Thiele ofreció, en base a dichos porcentajes, las siguientes estimaciones sobre el número de homosexuales en Alemania: "El uno por ciento de los 56 millones de habitantes que tenemos en Alemania serían unas 560.000 personas, y, señores, esta estimación del número de homosexuales en Alemania es probablemente demasiado baja más que demasiado alta. Las mujeres homosexuales no están incluidas. Si tomamos el mismo porcentaje para las mujeres, y no hay razón para usar un número diferente, tenemos más de 1 millón de habitantes en Alemania, el 2.2\% según los cálculos del Comité Científico Humanitario, que no se han realizado en el aire. Estas personas, sin ninguna falta personal, están sujetas a una ley excepcional y deben esperar las penas más severas sin poder cambiar su naturaleza ni la responsabilidad penal por sus acciones. Es una condición escandalosa sujetar a más de 1 millón de personas a las disposiciones del párrafo 175, amenazarlas con castigos, aunque no se les puede atribuir una culpa personal." (Hirschfeld 1905, p. 984).

Bajos las disposiciones del párrafo 175 del Código Penal, habían sido castigadas por "fornicación antinatural" en toda Alemania 585 personas en 1900, 491 personas en 1899, 484 personas en 1895, 412 personas en 1890, y 391 personas en 1885. Este era un porcentaje estable y al mismo tiempo ridículo y completamente arbitrario de las relaciones homosexuales que tenían lugar en Alemania. Thiele ofrecía las siguientes estimaciones: "Supongamos con el Comité Científico-Humanitario -y los cálculos no están hechos en el aire-, que tenemos 1.260.000 personas homosexuales en Alemania. Si de éstas la mitad son

17 Una referencia al libro de Magnus Hirschfeld, Berlins drittes Geschlecht (El tercer sexo de Berlín), Berlin und Leipzig: Verlag von Hermann Seemann Nachfolger, 1904. Hay versión francesa: Les homosexuels de Berlin : Le troisième sexe, Paris: Librairie médicale et scientifique Jules Rousset, 1908, 103 pp. Ambas versiones están disponibles online en archive.org 
mujeres, entonces quedan 600.000 hombres homosexuales. Si estimamos que sólo dos quintas partes de estos 600.000 hombres homosexuales tienen la edad suficiente para ser penalmente responsables, entonces nos quedan 248.000 personas homosexuales, adultas, de sexo masculino en Alemania -alrededor de una cuarta parte [del total de homosexuales]. Suponiendo que cada uno de estos 250.000 hombres practica una vez por semana el acto homosexual, multiplicando por 52 tenemos un número de 13 millones de actos homosexuales cometidos anualmente en Alemania por hombres que son potencialmente punibles, de los cuales tan sólo 533 o 600 son castigados." (Hirschfeld 1905, p. 987.)

A la afirmación de los conservadores de que la despenalización de la homosexualidad debilitaría al ejército, Thiele contestaba diciendo que "la fuerza militar del imperio, si vamos a entrar en ella, se debilita por la brutal escasez de viviendas en las grandes ciudades, por la mala nutrición debida a los bajos salarios de los trabajadores, por muchos otros abusos sanitarios en las comunidades grandes y pequeñas, y no por las acciones de los homosexuales." (Hirschfeld 1905, p. 988.)

Después de recordar el número de suicidios, así como los delitos de chantaje, a los que la penalización de la homosexualidad daba lugar, Thiele recordaba que las "tendencias homosexuales se pueden encontrar en todos los estratos de la población, en todas las edades, en ambos sexos, en todas las ocupaciones" (Hirschfeld 1905, pp. 990-991).

Este informe de Thiele fue rechazado con vehemencia por el diputado del Partido del Centro católico, Johann Thaler, en una intervención también reproducida por Hirschfeld en su revista. En su respuesta, después de pedir a Thale que no confundiera homosexualidad con pederastia como solían hacer los partidos de derecha (Hirschfeld 1905, p. 1026), Thiele resumió sus argumentos de la siguiente manera:

Como socialdemócratas, otros párrafos del Código Penal nos parecen aún más peligrosos, mucho más fatídicos y mucho más injustos que el párrafo 175. Pero eso no impide que defendamos un cambio en la ley que consideramos legítimo. Y cuando se nos dice que la moral, que el bien común requieren que el párrafo permanezca como está -ah, señores, todo en el mundo ha sido justificado haciendo referencia a la supuesta "moralidad" y a la preocupación por el "bien común"; la Inquisición, la caza de brujas, todo; y aquellos que se han enfrentado a instituciones anticuadas siempre han sido presentados como perturbadores, como enemigos de la moralidad. Ahora es lo mismo con el párrafo 175. Finalmente, debemos romper con los vestigios de la Edad Media que todavía tenemos en nuestra legislación, y la modificación del párrafo 175 es un cambio en ese sentido. Por lo tanto, los instamos a que acepten nuestra petición. (Hirschfeld 1905, p. 1029)

La petición fue rechazada por el pleno del Reichstag con los votos de la derecha, el Partido del Centro y la mayoría de los diputados del Partido Nacional Liberal, pero esta vez con un giro perverso: el Partido del Centro católico propuso que el párrafo 175 fuera reemplazado por un nuevo párrafo, que llevaría el número 250, para hacer extensiva la penalización de la homosexualidad a las mujeres lesbianas (Thiele 1909b, p. 1564). Aun así, Hirschfeld consideró al debate como "un paso importante para nuestro movimiento; esta es la primera vez que el parlamento alemán, quizás la primera vez que cualquier parlamento, ha discutido sobre el bienestar y los problemas de los homosexuales en sesiones abiertas" (Hirschfeld 1905, p. 1037).

En 1907 el Comité Científico-Humanitario presentó nuevamente su petición al Reichstag, en el marco del affaire Eulenburg, una serie de cortes marciales y de cinco juicios civiles en torno a acusaciones de homosexualidad contra miembros prominentes del gabinete y del entorno del Kaiser Wilhelm II durante los años 1907-1909. El escándalo se centró en las acusaciones de homosexualidad lanzadas por el periodista Maximilian Harden contra Philipp, Príncipe de Eulenburg-Hertefeld, y el general Kuno, conde von Moltke.

Según Hirschfeld, "el único que alzó nuevamente su voz a favor de los homosexuales en el Reichstag fue el viejo y desafortunadamente enfermo Bebel", en la sesión del viernes 29 de noviembre de 1907 (Hirschfeld 1908a, p. 631). Hirschfeld reprodujo a continuación el discurso de Bebel en el Jabrbuch 
für sexuelle Zwischenstufen (Hirschfeld 1908a, pp. 634-637). Bebel concluía diciendo: "caballeros, no tienen idea de cuántos hombres respetables, honorables y buenos, incluso en las posiciones más altas, se suicidan año tras año, algunos por vergüenza, los demás por miedo al chantajista... ¿Puede persistir el párrafo 175 en tales circunstancias?” (Hirschfeld 1908a, p. 637) La petición fue nuevamente rechazada, entre otras cosas por la actitud equívoca de tres diputados del SPD en el Reichstag (Geck, Sachse y Schwartz), quienes, según Hirschfeld, "arrastrados por el estado de ánimo momentáneo abandonaron completamente las posiciones tradicionales de su partido". ${ }^{18}$

La despenalización de la homosexualidad fue abandonada por el Partido Socialdemócrata de Alemania, junto con muchas otras demandas democráticas, después de que abandonó su programa revolucionario en 1914 y se convirtió en un partido del gobierno burgués desde 1918 en adelante. No obstante, está claro que la despenalización de la homosexualidad por el gobierno bolchevique en 1922 no fue un acontecimiento casual ni específicamente ruso, sino un producto de las posiciones de principio de los marxistas al respecto, ya en la época de la Segunda Internacional -más precisamente, un resultado del rescate del programa democrático de las revoluciones burguesas por los partidos socialistas y comunistas, ante su abandono por parte de la burguesía, que adoptó posiciones cada vez más reaccionarias ante el ascenso de la clase obrera.

\section{La penalización de la homosexualidad masculina en Rusia}

La prohibición militar de la sodomía fue introducida en Rusia por Pedro el Grande en 1716, en el marco de la imposición a los soldados y marineros de nuevas formas de disciplina inspiradas en las lecciones de la "revolución militar" europea. La criminalización de la homosexualidad masculina fuera del ejército data de 1835, cuando el zar Nicolás I extendió esta regulación a la población civil masculina en el nuevo Código Penal. En este código, y en el que lo suplantó en 1845, la sodomía consensual fue castigada con el exilio a Siberia (bajo lo que luego fue el artículo 995 del Código Penal), y la sodomía agravada, es decir, practicada con menores o mediante el uso de la fuerza o mediante el abuso de un puesto de autoridad, fue castigada con el exilio con trabajos forzados (artículo 996). ${ }^{19}$

El artículo 995 del Código Penal ruso de 1845 contra la sodomía voluntaria era prácticamente una letra muerta en Rusia hacia el final de la era imperial. Los casos de violación (изнасилование) de hombres y niños constituían el delito sexual entre personas del mismo sexo más frecuentemente perseguido por los tribunales zaristas. Se estimó que por cada condena debida al artículo 995, había cuatro debidas al artículo 996 (que penalizaba el uso de la fuerza o el abuso de la dependencia de la víctima o de un menor) durante los años comprendidos entre 1874 y 1904 (Healey 2001, pp. 80-81, 95).

La ley zarista no decía nada explícito acerca del sexo entre mujeres, paradójicamente debía a si estatus legal inferior: las mujeres sólo alcanzaron la igualdad jurídica con los varones como consecuencia de la revolución bolchevique.

Entre los defensores más articulados de la emancipación homosexual en la Rusia imperial se encontraban los abogados liberales, quienes argumentaban desde los principios de la secularización, el derecho a la privacidad y la autonomía personal, es decir, no desde la posición de sujetos homosexuales, sino desde la de juristas luchando por crear un régimen liberal basado en el "estado de derecho" burgués. La ausencia de un movimiento consciente de homosexuales que pidiera la despenalización de la homosexualidad en la Rusia zarista no debe considerarse como inusual, ya que sólo en Alemania existía una comunidad homosexual organizada.

\footnotetext{
18 Magnus Hirschfeld, "Einleitung und Situations-Bericht", Vierteljabrsberichte des Wissenschaftlich-bumanitären Komitees, Jg. 1, 1909, p. 20. Citado en Herzer 2017, pp. 177-178.

${ }_{19}$ En 1903 la revista de Hirschfeld publicó un estudio sobre el estatus jurídico de la homosexualidad masculina en el Código Penal zarista (Nabokoff 1903).
} 
Como en Francia y en otras partes de Europa, las más influyentes defensas rusas de la homosexualidad provinieron de obras literarias y de la crítica cultural, es decir, fueron producto del esfuerzo individual más que colectivo. Alas (Крылья), una novela de Mijaíl Kuzmín (un poeta, novelista y músico proveniente de una familia de la nobleza) publicada en 1906, fue la primera novela rusa de temática homosexual y causó un gran escándalo cuando apareció. El libro de Magnus Hirschfeld, El tercer sexo de Berlin (Berlins Drittes Geschlecht), originalmente publicado en 1904, fue traducido al ruso y publicado en 1908 en San Petersburgo, en una edición a cargo del profesor V.N. Pirogov. ${ }^{20}$

La prostitución masculina era practicada en Rusia mayormente en casas de baños, donde a menudo se explotaba sexualmente a menores. Las casas de baños funcionaban como burdeles masculinos de manera similar a los prostíbulos en los que se practicaba la prostitución femenina "licenciada" (dichos prostíbulos son prácticamente la única fuente de información existente sobre relaciones sexuales y parejas lesbianas en la Rusia zarista). Los informes sobre prostitución masculina organizada en la casa de baños cesan después de la revolución de 1917. (Healey 2001, p. 35)

\section{La eliminación del estatuto antisodomía en 1922}

El Gobierno Provisional burgués nacido de la revolución de febrero de 1917 no hizo nada por la liberación de los homosexuales rusos, la despenalización de la homosexualidad comenzó a ser debatida recién después de la revolución bolchevique de octubre de 1917.

Ya el primer borrador del Código Penal, redactado durante el periodo del gobierno de coalición entre los bolcheviques y los socialistas revolucionarios de izquierda en 1918, despenalizaba la homosexualidad. Pocas semanas después de la revolución de octubre de 1917, el Comisariado de Justicia, encabezado por Isaak Shteinberg, un socialista revolucionario de izquierda, redactó un estatuto penal como parte de un ambicioso Código de Leyes de la Revolución Rusa. El artículo relevante en el estatuto de Shteinberg se titulaba "sodomía" (мужеложство), у se incluyó dentro de un capítulo específicamente dedicado a los delitos sexuales encabezado "Sobre la conducta indecente" (неприличие). La ley de sodomía resultante legalizaba las relaciones sexuales consensuales entre adultos, definidos como personas de dieciséis años o más, aunque el consentimiento informado de adolescentes de catorce y quince años podía exonerar de penas a la sodomía con ciertos jóvenes también. (Healey 2001, p. 116)

El primer Código Penal ruso soviético, adoptado finalmente el 1 de junio de 1922 (Уголовный кодекс РСФСР 1922 гоАа), despenalizó la homosexualidad masculina. La sodomía y el incesto no fueron nombrados en absoluto en el nuevo código. Se abandonaron los límites de edad explícitos para el consentimiento, y en su lugar se introdujo el concepto de "pubertad" (зрелости: madurez sexual), que se determinaría por la opinión médica en cada caso. Cuando en 1926 se publicó un Código Penal revisado de la RSFSR, se reafirmó el mismo lenguaje y los mismos principios, incluyendo la ausencia de una prohibición de las relaciones consensuales entre personas del mismo sexo.

La despenalización de la homosexualidad convirtió a la Rusia soviética en la potencia más importante desde la Francia revolucionaria en despenalizar las relaciones sexuales entre personas del mismo sexo, mientras que las condenas por "delitos" similares iban desde cinco años en Alemania a cadena perpetua en Inglaterra (por buggery o "sodomía"). G.V. Chicherin, el Comisario del Pueblo de Asuntos Exteriores entre 1918 y 1930, fue un ejemplo de homosexual que ocupó un puesto prominente en el gobierno bolchevique. ${ }^{21}$

20 Магнус Хиршфеяьд, Третий пол Берлина. (Аокументы больиого столичного города) / пер. с нем., реА. проф. В.Н. Пирогова. СПб.: СПб. Коммерч. Типо-Аитография Вименчик, 1908.

${ }^{21}$ El primer Código Penal de la República Soviética de Azerbaiyán de febrero de 1923, a diferencia del código de la República Soviética de Rusia, prohibía la "sodomía" (мужеложство), al igual que los Códigos Penales de las Repúblicas Soviéticas de Uzbekistán, adoptado en 1926, y Turkmenistán, adoptado en 1927. En Uzbekistán era común la práctica de la prostitución masculina, a la cual eran sometidos sobre todo menores, conocidos como bacha (plural bachi), quienes eran organizados en burdeles o "grupos de baile" por proxenetas que reclutaban niños en colusión con sus padres y tutores. Los legisladores 


\section{Un caso de matrimonio homosexual en la Rusia Soviética temprana (1922)}

En 1927 el psiquiatra A.O. Edelshtein describió un caso de matrimonio entre mujeres que había tenido lugar en 1922 en la Rusia soviética. Uno de los cónyuges, Evgeniia Fedorovna M., se había presentado a sí misma como un hombre desde que había quedado huérfana en 1915, a los diecisiete años. Durante la revolución, había encontrado trabajo en la Cheka como instructora política, en "órganos de investigación penales", y participó en "requisas y búsquedas de monasterios"; luego viajó al frente sur, donde "participó en operaciones contra el bandidaje". Durante este tiempo había alterado sus documentos de identidad, adoptando el nombre masculino Evgenii Fedorovich; también comenzó a tener relaciones sexuales con una serie de mujeres.

En 1922, mientras estaba asignada por la GPU en una ciudad provincial, Evgeniia conoció y cortejó a "S.", una empleada postal, y concluyeron un matrimonio oficialmente registrado, con Evgeniia presentando su documento de identidad alterado (masculino). Edelshtein, que parece haber podido entrevistar a S., informó que al principio esta mujer no sospechó que su "esposo" no era hombre. Poco después del matrimonio, Evgeniia finalmente admitió ante S. que era una mujer. Sin embargo, esto no puso fin a su relación.

La indiscreción de Evgeniia "llamó la atención sobre sí misma y generó dudas sobre su sexo", aparentemente inspirando a las autoridades locales a acusarla de un "crimen contra la naturaleza". Evgeniia ganó el juicio, y el Comisariado del Pueblo de Justicia se vio obligado en 1922 a reconocer el matrimonio entre las dos mujeres como "legal, porque fue concertado por consentimiento mutuo". La pareja permaneció unida durante otros dos o tres años. Después S. tuvo un romance con un compañero de trabajo masculino, con quien tuvo un hijo que Evgeniia legalmente adoptó. Las dos mujeres y el niño formaron una familia hasta que el regimiento de la GPU de Evgeniia fue trasladado a Moscú. Evgeniia parece haber abandonado a su esposa e hijo para seguir su carrera en la GPU, sólo para ser despedida en 1925, poco después de la llegada a la capital.

Evgeniia Fedorovna M. afirmaba que las mujeres de su tipo "consideran que su sexo es un malentendido y desean transformarse en personas del sexo opuesto", pero no argumentaba por una cirugía para transformar su cuerpo. En cambio, abogaba por la aceptación del "amor entre personas del mismo sexo... como una variación particular" en la humanidad. Una vez que los miembros del "sexo intermedio" dejaran de ser "oprimidos y sofocados por su propia falta de conciencia y por la falta de respeto pequeñoburguesa", sus vidas serían socialmente valiosas. ${ }^{22}$

\footnotetext{
bolcheviques estaban decididos a erradicar esta forma de prostitución masculina, que involucraba la pederastia. Estos delitos se agruparon con otros que constituían "supervivencias de costumbres primitivas", en contraste con los delitos sexuales, que fueron ubicados como una subsección separada de los delitos contra la persona (Healey 2001, p. 319, nota 21). Del mismo modo que los juristas revolucionarios, al mismo tiempo que combatían la prostitución, habían rechazado la criminalización de las prostitutas en la República Rusa (Bronner 1936, Мирошниченко 2013), en los Códigos de Uzbekistán у Turkmenistán las prostitutas masculinas mismas no eran penalizadas, pero prácticamente todos los demás aspectos de la prostitución masculina fueron prohibidos. El "proxenetismo y reclutamiento de hombres para sodomía" era una ofensa aparte, penalizada de manera similar al reclutamiento (explícitamente de mujeres) para la prostitución en el Código Penal soviético. Único también en la legislación soviética fue el artículo 278 del Código Penal de las República Soviética de Uzbekistán, que prohibía el acoso sexual a hombres. Su lenguaje invirtió el género del estatuto pionero de la República Soviética Rusa contra el acoso sexual de mujeres, adoptado por primera vez en 1923. Pero la lógica detrás de esta medida era la misma: se temía que los hombres o los adolescentes en situaciones de dependencia cayeran en el riesgo de la prostitución (Healey 2001, pp. 159-161, 319-320).

22 Healey 2001, pp. 68, 70, 130, 284. El caso y el testimonio de Evgeniia se presentan en ЭАельштейн 1927. Sobre las experiencias subjetivas de los homosexuales en la Rusia soviética temprana, muchos de los cuales se identificaban con el nuevo régimen como un movimiento liberador, ver Ролаугина 2016а у 2016b.
} 


\section{Las relaciones de Magnus Hirschfeld con la Rusia soviética}

En enero de 1923, durante una visita a Berlín, Semashko, el Comisario del Pueblo de Salud, afirmó ante los miembros alemanes del movimiento internacional para la reforma sexual que la legalización soviética de las relaciones homosexuales entre hombres era una medida deliberadamente emancipadora, parte de la revolución sexual. Las actividades de investigación y de reforma sexual del Instituto de Investigación Sexual del Dr. Magnus Hirschfeld, fundado en Berlín en 1919, eran seguidas con interés por los "higienistas sociales" soviéticos. Semashko visitó el Instituto con una delegación de médicos soviéticos, quienes pidieron que fuera proyectado el film Anders als die Andern (Diferente de los otros), una documentación cinematográfica sobre el amor homosexual hecha en 1919 con la participación de Hirschfeld. ${ }^{23}$ La revista del Instituto informó que los espectadores soviéticos expresaron asombro ante el hecho de que la película hubiera sido prohibida en Alemania, y que Semashko se sentía orgulloso de que en la nueva Rusia la anterior penalización de la homosexualidad hubiera sido abolida. También explicó que no se habían producido consecuencias infelices de ningún tipo como resultado de la eliminación del párrafo del Código Penal ruso que criminalizaba la homosexualidad, ni tampoco nadie había planteado el deseo de que se reintrodujera la pena en cuestión. ${ }^{24}$

En 1925, el "higienista social" de la Universidad de Moscú Grigorii Batkis publicó en Berlín un folleto en alemán titulado La revolución sexual en Rusia. En el mismo, Batkis decía lo siguiente en relación a la homosexualidad en la legislación soviética:

La legislación no interfiere en ninguna relación sexual, siempre que la misma tenga lugar entre dos adultos sin ningún tipo de compulsión. La naturaleza de las actividades sexuales resultantes de tal relación es un asunto privado entre las personas involucradas. La cuestión de la moralidad pública no existe para la legislación en este caso.

La legislación soviética considera a la homosexualidad, la sodomía y todas las otras formas de gratificación sexual que la legislación europea presenta como una ofensa pública contra la moralidad de forma exactamente igual a las así llamadas relaciones sexuales "naturales". Todas las formas de relación sexual son asuntos privados. La cuestión de la persecución penal sólo surge cuando se usa la fuerza y la coacción, como en el caso de una agresión o de que se haya infringido un daño a los intereses de otra persona. (Batkis 1925, p. 22).

Más tarde, Batkis y otros representantes soviéticos hablaron en las conferencias de la Liga Mundial para la Reforma Sexual, la cara internacional del Instituto de Investigación Sexual de Hirschfeld.

A fines de junio de 1926, Hirschfeld viajó a Moscú y Leningrado como invitado del gobierno, probablemente a iniciativa de Semashko. Hirschfeld dio el primer informe de su viaje a Rusia el 4 de noviembre de 1926, en un evento organizado por la "Sociedad de Amigos de la Nueva Rusia" en el Hotel de Berlín Russischer Hof. Dicha conferencia, titulada "La reorganización de la vida sexual en la Rusia soviética", trató no solamente de la homosexualidad sino también de la igualdad jurídica de la mujer y el hombre, de las nuevas leyes de matrimonio civil y de divorcio, de la protección estatal para la mujer y el niño, de la igualación de los derechos de los hijos legítimos e ilegítimos, de la prohibición de la violencia doméstica, de las provisiones para las familias monoparentales, de la planificación del embarazo mediante métodos anticonceptivos, de la legalización del aborto, de la prevención de las enfermedades sexuales, de la rehabilitación social de las prostitutas, del derecho otorgado a los presos a tener relaciones sexuales heterosexuales en las cárceles y de la coeducación. En dicha oportunidad, Hirschfeld afirmó que "desde la revolución la Rusia soviética ha realizado una obra gigantesca", y que "el desmantelamiento del viejo sistema y la construcción de una nueva sociedad, de una nueva relación entre sexo y sociedad, es un logro

${ }_{23}$ Disponible en youtube, con subtítulos en inglés, en https://youtu.be/H3PBJmWWwGI

${ }^{24}$ Las observaciones de Semashko fueron informadas en "Jahresbericht 1922/23", Jabrbuch für sexuelle Zwischenstufen, Band 23, 1923, pp. 211-212. 
que hace época". Sobre la posición de los homosexuales, hacía la siguiente observación crítica: "La homosexualidad no es penalizada en Rusia (sin embargo, sí es penalizada la seducción de menores, para quienes la madurez sexual se especifica como la edad individual de consentimiento). Extrañamente, la evaluación de la homosexualidad en Rusia se corresponde completamente con la visión generalizada entre nosotros: se considera la homosexualidad como algo degenerado, no proletario." Hirschfeld consideraba que este prejuicio carecía completamente de sentido (Hirschfeld 1926, p. 40).

Anatoli Lunacharsky, el Comisario del Pueblo para la Educación, visitó el Instituto de Ciencias Sexuales de Hirschfeld en 1927 e informó de dicha visita con entusiasmo en el diario Krasnaya gazeta de Leningrado, afirmando que el aprendizaje debía ser mutuo: "La visita del Prof. Hirschfeld y su amistad con la Rusia Roja son necesarios, no sólo porque él puede encontrar la realización de sus ideas entre nosotros, sino también porque nosotros podemos aprender mucho de él. La legislación estatal, por supuesto, no significa en sí misma la cura de todas las heridas abiertas de nuestra vida sexual individual y social, y también nosotros necesitamos la investigación científica a gran escala, atenta, exhaustiva, y probablemente también organizativamente coordinada, de estos problemas, así como las instituciones necesarias para su solución práctica apropiada." Las propuestas de crear un Instituto de Sexología soviético y de una cátedra en ciencias sexuales en una universidad soviética, que Lunacharski hizo en dicho artículo, nunca se materializaron (Herzer 2017, p. 338).

A finales de la década de 1920, los higienistas sociales soviéticos desempeñaron un papel prominente en la Liga Mundial para la Reforma Sexual, debido a la legislación bolchevique radical en materia sexual. En las primeras conferencias de la Liga, la despenalización soviética de la homosexualidad masculina era aclamada rutinariamente. La presencia de Alexandra Kollontai, junto con Batkis y el profesor ucraniano Nikolai Pasche-Oserski, en el "Comité Internacional" de directores de dicha organización le dio la apariencia de un apoyo oficial soviético, si bien Kollontai, a diferencia de Semashko y Lunacharski, nunca conoció a Hirschfeld personalmente ni participó en los congresos de la Liga Mundial para la Reforma Sexual. ${ }^{25}$

Al mismo tiempo, los miembros del Partido Comunista alemán (KPD) apoyaban públicamente las actividades del Instituto de Hirschfeld. Por ejemplo, Martha Ruben-Wolf, una médica y miembro del KPD, publicó, en 1929, un folleto titulado Abtreibung oder Verbütung? (之Aborto o anticoncepción?), en que recomendaba la despenalización del aborto y su práctica gratuita en los hospitales, así como la entrega de anticonceptivos con receta médica pagados por las cajas de seguros para enfermedad. Al igual que el aborto, las prácticas anticonceptivas tampoco eran enseñadas con métodos científicos en las facultades de medicina alemanas, por lo que la autora finalizaba recomendando una serie de libros de texto en alemán para médicos y legos sobre el tema, así como un listado de los métodos anticonceptivos más eficientes disponibles en aquel entonces y de servicios de asesoramiento (Beratungstellen), entre ellos el Institut für Sexualwissenschaft dirigido por el Dr. Magnus Hirschfeld en Berlín (Ruben-Wolf 1929, pp. 10, 13, 16).

\footnotetext{
${ }^{25}$ La pertenencia de "Alexandra Kollontay" en el Comité es notada en World League for Sexual Reform, Proceedings of the 2nd Congress (Copenhagen, 1928) (Copenhagen, 1929, p. 9). Una nota para sí misma en el archivo del Partido sugiere que Kollontai puede haber tenido sentimientos encontrados sobre su asociación con la cuestión sexual en 1923: "La sociedad inglesa para el estudio de la psicología sexual (British Society for Sex Psychology) me eligió como miembro honorario, al mismo nivel que Havelock Ellis y otros. Me pregunto: ¿se publicará en nuestros periódicos? Después de todo, no muchas mujeres rusas están nominadas a asociaciones científicas, mucho menos en la "orgullosa" Gran Bretaña... Pero luego me di cuenta de que no hay necesidad. ¿Psicología sexual? ¿Qué es eso? ¿Experto en cuestiones sexuales? ¿'Spets' (especialistas) a cargo de 'cuestiones sexuales'? Cinismo, vulgarizaciones..."; RGASPI, f. 134, op. 4, d. 17, 1. 9. (Healey 2001, p. 309, nota 33).
} 


\section{El artículo sobre la homosexualidad en la Gran Enciclopedia Soviética}

En 1930, el artículo de psiquiatra Mark Sereiskii sobre la homosexualidad para la Gran Enciclopedia Soviética, luego de una serie de consideraciones médicas hoy obsoletas ${ }^{26}$, refrendaba la campaña de Hirschfeld por la emancipación homosexual, afirmando:

La dirección del interés sexual hacia la búsqueda de individuos de su mismo sexo obliga a los homosexuales a violar las así llamadas normas de comportamiento generalmente aceptadas. En el exterior, y en la Rusia prerrevolucionaria, estas violaciones de las reglas de conducta generalmente aceptadas eran penalizadas por "leyes de moralidad" especiales. Además del hecho de que esta legislación contra el sesgo biológico es absurda en sí misma y no produce resultados reales, actúa en forma extremadamente perjudicial para la psique de los homosexuales. Hasta el día de hoy, en los países capitalistas avanzados, la lucha por la abolición de estas instituciones hipócritas está lejos de haber terminado. Por eso, en Alemania, Magnus Hirschfeld lidera una lucha particularmente apasionada y sin éxito para abolir la ley contra la homosexualidad. La legislación soviética no conoce los así llamados delitos contra la moral. Nuestra legislación, basada en el principio de la protección de la sociedad, castiga sólo los casos en los que el objeto de interés de los homosexuales, son menores de edad (artículos 151, 152 del Código Penal de la RSFSR). (Серейский 1930)

Sereiskii concluía abogando por la integración de los homosexuales y afirmaba que "nuestra sociedad, mediante una serie de medidas preventivas y de salud, crea todas las condiciones necesarias para que el choque de los homosexuales con la vida sea indoloro, y para que la sensación de extrañamiento, usual en dichos choques, se disuelva en el nuevo colectivo."27

\section{La repenalización de la homosexualidad en 1934}

El periodo de despenalización de la sodomía en la Rusia soviética se extendió desde 1922 hasta 1934, cuando Stalin le puso fin. En septiembre de 1933, Guénrij Yagoda, el Comisario del Pueblo de Asuntos Internos, sugirió a Stalin que una ley contra la "pederastia" era necesaria para todas las repúblicas soviéticas. Yagoda informó a Stalin que la policía secreta había realizado redadas en Moscú y Leningrado, arrestando 130 hombres presuntamente vinculados a "salones, centros, antros, grupos, y otras organizaciones de pederastas". El objetivo de estas "organizaciones" era supuestamente el espionaje, lo cual captó la atención de Stalin. Afirmando que "esos canallas deben recibir un castigo ejemplar", Stalin ordenó a Yagoda la redacción de una nueva ley; el borrador fue apoyado fuertemente por sus colegas del politburó Kaganovich y Viacheslav Molotov (Healey 2002, p. 362).

El 17 de diciembre de 1933, se publicó la Resolución del Comité Ejecutivo Central de toda Rusia sobre la homosexualidad, que se convirtió en ley el 7 de marzo de 1934. Dicha ley fue agregada como artículo 154-a del Código Penal de la República Socialista Federativa de Rusia el 1º de abril de 1934 (en su posterior numeración, artículo 121), y penalizaba las relaciones sexuales voluntarias entre varones en las siguientes palabras:

154-a. Las relaciones sexuales entre hombres [recibirán una pena de] encarcelamiento por un término de tres a cinco años. La sodomía (мужеложство) cometida con el uso de la violencia o usando la

\footnotetext{
${ }_{26}$ Recordemos que la American Psychiatric Association eliminó el diagnóstico de "bomosexuality" como enfermedad de su Diagnostic and Statistical Manual recién en 1973.

27 "Наше законодательство, исходя из принципа защиты общества, предусматривает наказание лишь в тех случаях, когда объектом интереса гомосексуалистов становятся малолетние и несовершеннолетние". (Серейский 1930, р. 596.)
} 
posición dependiente de la víctima [recibirá una pena de] encarcelamiento por un término de cinco a ocho años. ${ }^{28}$

En otras palabras, en el derecho penal estalinista, la homosexualidad masculina pasó a pertenecer a los crímenes contra la persona y a castigarse con una pena de prisión de hasta cinco años -y en circunstancias agravantes (por ejemplo, cometer sodomía con menores) con un máximo de 8 años. Las operaciones secretas en Moscú y San Petersburgo contra hombres homosexuales, orquestadas por la OGPU, comenzaron en el verano de 1933. El primer caso judicial bajo la nueva legislación contra la sodomía llegó al sistema legal convencional de Moscú (a diferencia de los tribunales de la OGPU/NKVD) después de los arrestos de homosexuales que tuvieron lugar en noviembre de 1934 (Healey pp. 209-210). La asociación con Hirschfeld y el Comité Científico-Humanitario, que era una política oficial a comienzos del gobierno soviético, se convirtió bajo el estalinismo, a partir de 1933, en un síntoma de inclinaciones "contrarrevolucionarias" y de "convicciones fascistas".

En mayo de 1934 Harry Whyte, un miembro del Partido Comunista británico, escribió una carta a Stalin en la que la planteó la pregunta: "¿puede un homosexual ser considerado alguien digno de ser miembro del Partido Comunista?". En ese momento, Whyte, que era homosexual, estaba trabajando en Moscú en el Moscow Daily News. Cuando se enteró de la nueva ley, le escribió la carta a Stalin preguntándole cómo podía justificarla. Whyte señaló que la nueva ley estaba anulando todo el progreso que había tenido lugar en relación a la despenalización de la homosexualidad desde la Revolución de Octubre. La respuesta manuscrita de Stalin se conserva en los archivos soviéticos, en la primera página: "Para el archivo. Idiota y degenerado. J. Stalin" («B архив. ИАиот и дегенерат. И. Сталин»). (Whyte 1934)

\section{"Destruyan a los homosexuales y el fascismo desaparecerá"}

La primera explicación pública del régimen estalinista sobre los "motivos" para la recriminalización de la homosexualidad masculina fue el artículo de Máximo Gorki, "Humanismo Proletario", publicado en Pravda e Irvestiia el 23 de mayo de 1934. Dicho artículo colocó la cuestión en términos de la guerra de propaganda entre el fascismo y el "comunismo". Los temas de esta guerra eran la degradación moral y la seducción de la juventud por el fascismo. Gorki contrapuso una Rusia míticamente pura a un Occidente demasiado civilizado, declarando que el humanismo proletario estaba transformando las enormes reservas de energía "bárbara" de Rusia en "energía intelectual" productiva. Mientras tanto, el capitalismo utilizaba al fascismo para movilizar a los vástagos de la burguesía, física y moralmente agotados, hijos de alcohólicos, histéricos y sifilíticos." En las miles de caras grises y disecadas es especialmente raro ver individuos sanos y de sangre pura, porque son pocos". Entre los "cientos de hechos que hablan de la influencia destructora y desmoralizadora del fascismo", la homosexualidad era una de las características más "repugnantes". Lo que estaba en juego no era sólo la pureza y la salud de la población, sino también su cultura. Donde el proletariado gobernaba, la homosexualidad era considerada una fuerza que corrompía a los jóvenes y era castigada, mientras "en la tierra de los grandes filósofos, científicos y músicos [Alemania], se practica libre e impunemente". Gorki negaba que los homosexuales pudieran constituir una minoría social digna de ser salvaguardada por el estado obrero como los judíos o "los hindúes, chinos y negros desarmados", llegando incluso a lanzar la consigna, "Destruyan a los homosexuales y el fascismo desaparecerá" ("Уничтожьте гомосексуалистов - фашизм исчезнет"). ${ }^{29}$

\footnotetext{
28 Уголовный Кодекс РСФСР редакции 1926/Редакция 11.01.1956 [El Código Penal de la RSFSR en 1926 / Edición 11.01.1956]. Disponible online in https://ru.wikisource.org/

29 Максим Горький, "Пролетарский гуманизм", Впервые напечатано одновременно в газетах "Правда", номер 140 от 23 мая 1934, и "Известия ЦИК СССР и ВЦИК", номер 119 от 23 мая 1934. [Máximo Gorki, "Humanismo Proletario", publicado por primera vez de forma simultánea en los diarios Pravda, $\mathrm{N}^{\circ}$ 140, 23 de mayo de 1934, e Iqvestiia ("Noticias del Comité Ejecutivo Central de la URSS y del Comité Ejecutivo Central"), No 119, 23 de mayo de 1934.] El mismo artículo fue publicado ese año en
} 
En una carta del 10 de junio de 1934 a uno de sus corresponsales, quien le pidió que escribiera un artículo para una revista francesa, Máximo Gorki escribió: "Recomiendo un artículo, 'Humanismo proletario' publicado en Pravda hace aproximadamente un mes. Este artículo fue muy aprobado por el camarada Stalin." ("Рекомендую статейку "Гуманизм пролетариата", напечатанную в "Правде" с месяц назаА. Эту статейку очень одобриц товарищ Сталин". $)^{30}$

En enero de 1936, el Comisario del Pueblo Nikolai Krylenko declaró que la homosexualidad es producto de la descomposición de las clases explotadoras; en una sociedad socialista, basada en principios saludables, esas personas no existirían. La homosexualidad estaba, por lo tanto, directamente "vinculada" con la contrarrevolución. Desde entonces, bajo el estalinismo los abogados y médicos soviéticos hablaron sobre la homosexualidad principalmente como una manifestación de la "decadencia moral de la burguesía", repitiendo literalmente los argumentos de los fascistas alemanes.

\section{Conclusión}

La despenalización de la homosexualidad fue un producto de las revoluciones burguesas. Dicha demanda, abandonada por los partidos burgueses a medida que el ascenso del proletariado impulsó a la burguesía a buscar un compromiso con los terratenientes, el clero y las monarquías de los diferentes países, fue recogida por los partidos obreros marxistas, tales como el Partido Socialdemócrata de Alemania antes de la Primera Guerra Mundial y el Partido Bolchevique en Rusia después de la revolución de octubre de 1917. La despenalización de la homosexualidad en Rusia bajo Lenin, con la adopción del primer Código Penal soviético en junio de 1922, fue revertida en marzo de 1934, en el marco de la reacción estalinista. El delito de sodomía fue reintroducido en la legislación de la RSFSR el 7 de marzo de 1934 y estuvo asociado con medidas que en 1936 prohibieron el aborto e hicieron el divorcio menos accesible -es decir, con una opresión creciente no solo de los varones homosexuales, sino también de las mujeres. La repenalización de la homosexualidad en Rusia duró hasta el 3 de junio de 1993 y afectó el destino de muchos miles de personas: el número total de condenas registradas durante la era de la recriminalización de la homosexualidad masculina (1934-93) ascendió a entre 25.688 y 26.076 personas (Healey 2001, p. 263).

El gobierno de Boris Yeltsin, que presidió sobre la restauración del capitalismo en Rusia, decidió despenalizar la homosexualidad en Rusia en 1993 como una concesión a la estrategia de contrarrevolución democrática adoptada por el imperialismo estadounidense ante la crisis de los regímenes estalinistas en Europa del Este, pero bajo el régimen bonapartista de Vladimir Putin, en un gesto a la Iglesia Ortodoxa rusa, la Duma aprobó una ley el 11 de junio de 2013 prohibiendo la "propaganda de relaciones sexuales no tradicionales" y "la diseminación de cualquier información que pueda despertar el interés de los menores en este tipo de relación". De acuerda a dicha ley, actualmente en vigencia, se pueden imponer multas fuertes a quienes proporcionen información sobre la comunidad lésbica, gay, bisexual y transgénero a menores de edad o realicen manifestaciones de orgullo gay, y los medios que diseminen dicha información pueden ser objeto de una suspensión de noventa días. (Marie 2016, p. 103)

alemán como "Gegen der Faschismus: Proletarischer Humanismus" ["Contra el fascismo: Humanismo proletario"] en la revista Rundschau über Politik, Wirtschaft und Arbeiterbewegung, Band 34, 1934. (Healey 2001, p. 189).

30 Архив А. М. Горького. (Горький 1951, р. б.) http://gorkiy.lit-info.ru/gorkiy/articles/article-361.htm 


\section{Referencias}

Anders als die Andern (Diferente de los otros) 1919 https:/ / youtu.be/H3PBJmWWwGI

Anónimo, "Krupp auf Capri", Vorwärts, 15. November 1902, pp. 2-3.

Assemblée Nationale Constituante de France 1791, Décret concernant le Code Pénal du 25 septembre 1791. https://archive.org/details/dcretconcernant100fran_13

Barbier, Edmond Jean François 1847, Journal historique et anecdotique du règne de Louis XV, publié pour la Société de l'histoire de France d'après le manuscrit inédit de la bibliothèque nationale par A. de la Villegille, Paris : Jules Renouard et cie.

Batkis, Grigorii 1925, Die Sexualrevolution in Rußland, Berlin: Syndikalist.

Bebel, August 1898, Die Frau und der Sozialismus, 29. Auflage, Stuttgart: Verlag von A. H. W. Dietz Nachfolger.

Bernstein, Eduard 1895a, “Aus Anlaß eines Sensationsprozesse” London, April 1895, Die neue Zeit, 13. 1894-95, 2. Bd. (1895), H. 32, pp. 171-176.

Bernstein, Eduard 1895b, "Die Beurtheilung des widernormalen Geschlechtsverkehrs" London, 6 May 1895, Die neue Zeit, 13. 1894-95, 2. Bd. (1895), H. 34, pp. 228-233.

Bronner, V. M. 1936, La lutte contre la prostitution en URSS, Moscou : Société pour les relations culturelles entre l'U.R.S.S. et l'étranger. [Вульф Моисеевич Броннер, Проституиия и пути ее ликвидачии. А.: ГМИ, 1931.]

Engels, Friedrich 1865, "Engels an Marx in London, Manchester, 11. März 1865", en Karl Marx und Friedrich Engels, Werke, Berlin: Dietz-Verlag, 1965, Band 31, pp. 96-98.

Fuchs, Hans 1904, "Jahrbuch für sexuelle Zwischenstufen unter besonderer Berücksichtigung der Homosexualität. Herausgegeben von Dr. Magnus Hirschfeld, Charlottenburg. Fünfter Jahrgang. Verlag von Max Spohr, Leipzig. : [Rezension]”, Die neue Zeit, 22. 1903-1904, 2. Bd. (1904), H. 40, p. 448.

Healey, Dan 2001, Homosexual Desire in Revolutionary Russia: The Regulation of Sexual and Gender Dissent, Chicago: Chicago University Press, 2001.

Healey, Dan 2002, "Homosexual Existence and Existing Socialism: New Light on the Repression of Male Homosexuality in Stalin's Russia", GLQ. A Journal of Lesbian and Gay Studies, Vol. 8, No. 3, pp. 349-378.

Herzberg, Wilhelm 1900, "Jahrbuch für sexuelle Zwischenstufen unter besonderer Berücksichtigung der Homosexualität. Herausgegeben unter Mitwirkung namenhafter Autoren vom wissenschaftlichhumanitären Komite Leipzig und Berlin. Leipzig 1899, Max Spohr. [Rezension]”, Die neue Zeit, 18. 18991900, 2. Bd. (1900), H. 31, pp. 123-124.

Herzen, W. 1898, "Die konträre Sexualempfindung und der \175 des Reichsstrafgesetzbuchs", Die neue Zeit, 16. 1897-98, 2. Bd. (1898), H. 44, pp. 555-561.

Herzer, Manfred 2017, Magnus Hirschfeld und seine Zeit, Berlin: Walter de Gruyter GmbH.

Hirschfeld, Magnus 1899, "Petition", Jahrbuch für sexuelle Zwischenstufen, I. Jahrgang, pp. 239-279.

Hirschfeld, Magnus 1903, "Jahresbericht 1902/3", Jahrbuch für sexuelle Zwischenstufen, V. Jahrgang, II. Band, pp. 1292-1354.

Hirschfeld, Magnus 1904, Berlins drittes Geschlecht, Berlin und Leipzig: Verlag von Hermann Seemann Nachfolger. [Primera edición en ruso: Магнус Хиршфеяьд, Третий пол Берлина. (Аокументь большого столичного города) / пер. с нем., реА. проф. В.Н. Пирогова. СПб.: СПб. Коммерч. ТипоАитография Вименчик, 1908.]

Hirschfeld, Magnus 1905a, "Jahresbericht 1903-1904", Jabrbuch für sexuelle Zwischenstufen, VII. Jahrgang, I. Band. 1905, pp. 647-728.

Hirschfeld, Magnus 1905b, "Jahresbericht 1904-1905", Jabrbuch für sexuelle Zwischenstufen, VII. Jahrgang, II. Band, 1905, pp. 949-1067.

Hirschfeld, Magnus 1908a, "Jahresbericht 1906-1908", Jahrbuch für sexuelle Zwischenstufen, IX. Jahrgang. 1908, pp. 621-728. 
Hirschfeld, Magnus 1908b, Les homosexuels de Berlin : Le troisième sexe, Paris: Librairie médicale et scientifique Jules Rousset. pp. 39-40.

Hirschfeld, Magnus 1926, "Sexualreform im neuen Rußland", Das neue Rußland, Jg. 3, Nr. 11/12,

Hirschfeld, Magnus 1930, Geschlechtskunde auf Grund dreißigï̈hriger Forschung und Erfahrung bearbeitet. Bd 3: Einblicke und Ausblicke, Stuttgart: Julius Püttmann.

Kennedy, Hubert 2002, Karl Heinrich Ulrichs: Pioneer of the Modern Gay Movement, San Francisco: Peremptory Publications.

Marie, Jean-Jacques 2016, La Russie sous Poutine: Au pays des faux-semblants, Paris : Payot.

Marx, Karl 1865, "Marx an Engels in Manchester, [London] 10 March [1865] ", en Karl Marx und Friedrich Engels, Werke, Berlin: Dietz-Verlag, 1965, Band 31, p. 96.

Nabokoff, Vladimir 1903, "Die Homosexualität im Russischen Strafgesetzbuch," Jahrbuch für sexuelle Zwischenstufen mit besonderer Berücksichtigung der Homosexualität, V. Jahrgang II. Band, 1903, pp. 11591171.

Ruben-Wolf, Martha 1929, Abtreibung oder Verbütung? Berlin: Internationaler Arbeiter Verlag.

Sibalis, Michael David 1996, "The Regulation of Male Homosexuality in Revolutionary and Napoleonic France, 1789-1815", in Jeffrey Merrick and Bryant T. Ragan, Jr. (eds.), Homosexuality in Modern France, Oxford University Press, 1996, pp. 80-101.

Taeger, Angela, und Rüdiger Lautmann 1992, "Sittlichkeit und Politik: $\$ 175$ im deutschen Kaiserreich (1871-1919)," en Angela Taeger (ed.), Männerliebe im alten Deutschland, Berlin: Sozialgeschichtliche Abhandlungen, pp. 239-268.

Thiele, Adolf 1909a, "Die Homosexualität in der Gesetzgebung", Sozialistische Monatshefte, $13=$ 15 (1909), H. 23190923 , pp. 1486-1493.

Thiele, Adolf 1909b, “Kann Homosexualität strafbar sein?”, Sozialistische Monatshefte, $13=15$ (1909), H. 24190924, pp. 1560-1567.

Ulrichs, Karl Heinrich 1869, Incubus. Urningsliebe und Blutgier. Eine Erörterung über krankhafte Gemüthsaffection und Zurechnungsfähigkeit, veranlasst durch den Berliner Criminalfall v. Zastrow. Mit 15 Fällen verwandter Natur. Als Fortsetzung der Schriften von Numa Numantius. Achte Schrift. Leipzig: A. Serbe's Verlag.

Verhandlungen des Deutschen Reichstags. Stenographische Berichte 1898, "Bebel, Abgeordneter", Reichstagsprotokolle, Reichstags. 16. Sitzung. Donnerstag den 13. Januar 1898, Berlin: Druck und Verlag der Norddeutschen Buchdruckerei und Verlags-Anstalt, pp. 410-418. http://www.reichstagsprotokolle.de/Blatt k9 bsb00002771 00462.html

Whyte, Harry 1934, "Can a homosexual be in the Communist Party?" (letter to Stalin of May 1934). [Гарри Уайт, "Может ми гомосексуал быть членом коммунистической партии? (1934)", Источник, № 5-6, 1993, С. 185-191.] Versión inglesa disponible online: www.marxist.com/letter-tostalin-can-a-homosexual-be-in-the-communist-party.htm

\section{Referencias en ruso}

Горький, Максим 1934, "Пролетарский гуманизм", "Правда", номер 140 от 23 мая 1934, и "Известия ЦИК СССР и ВЦИК", номер 119 от 23 мая 1934. [Máximo Gorki, "Humanismo Proletario", Pravda, No 140, 23 de mayo de 1934, e Izvestiia ("Noticias del Comité Ejecutivo Central de la URSS y del Comité Ejecutivo Central"), N 119, 23 de mayo de 1934. Versión alemana: Maxim Gorki, „Proletarischer Humanismus“, Rundschau über Politik, Wirtschaft und Arbeiterbewegung vom 31.05.1934, 3. Jg., Nr. 34, S. 1297-1299.]

Горький, Максим 1951, Избранные публичистические произведения: статьи, памфлеты, речи, М.: Гос. изА-во детской мит-ры. [Máximo Gorki, Obras publicísticas escogidas: Artículos, panfletos, discursos, Moscú: Editorial Estatal de Literatura, 1951.] 
Мирошниченко, Мария И. 2013, “Создание советов по борьбе с проституцией в начале 1920-х годов,” Вестник Южно-Уральского государственного университета. Серия: Сочиально-гуманитарные науки, Vol. 13, Nro. 1, pp. 41-45. [Maria Ilinichna Miroshnichenko, "La creación de Soviets de lucha contra la prostitución en la década de 1920", Boletín de la Universidad Estatal del Ural Sur. Serie: Ciencias Sociales y Humanas, Vol. 13, Nro. 1, 2013, pp. 41-45.]

Ролдугина, Ирина 2016b, "“Почему мы такие Аюди?”: Раннесоветские гомосексуалы от первого Аица: новые источники по истории гомосексуальных идентичностей в России. Ирина Ролдугина", Ab Imperio, Вол. 2, 2016, pp. 183-216. [Irina Roldugina, "‘¿Por qué somos así?’: Homosexuales de la era soviética temprana en primera persona: Nuevas fuentes sobre la historia de las identidades homosexuales en Rusia", Ab Imperio, Vol. 2, 2016, pp. 183-216.]

Ролдугина, Ирина 2016b, "Письма советских гомосексуалов второй половины 1920-х гг.", Ab Imperio, Vol. 2, pp. 217-258. [Irina Roldugina, "Cartas de homosexuales soviéticos de la segunda mitad de la década de 1920", Ab Imperio, Vol. 2, 2016, pp. 217-258.]

Серейский, Марк 1930, "гомосексуализм", Больщая советская энииклопедия, 17, С. 593-96. [Mark Sereiskii, "Homosexualidad”, Gran Enciclopedia Soviética, primera edición, 1930, tomo 17, pp. 59396.]

Швеков, Георгий В. 1970, Первый советский уголовный кодекс : Учебное пособие для студентов юридических институтов и факультетов, Москва: Высшая школа. [Georgy V. Shvekov, El primer Código Penal soviético: Un libro de texto para estudiantes de institutos y facultades de derecho, Moscú: Escuela Superior, 1970.]

ЭАельштейн, А. О. 1927, "К кАинике трансвестизма", Преступник и преступность, Москва: Иза-во Мосзаравотдела, 1927, Сборник II, С. 273-282. [А.O. Edelshtein, "Para la clínica del travestismo", El criminal y la criminalidad, Moscú: Editorial del Ministerio de Salud, 1927, Colección II, pp. 273-282.] 